\title{
ELECTRICITY METERS, WITH NOTES ON METER TESTING.
}

By H. A. Ratcliff and A. E. Moore, Associate Members.

(Paper reccived February I7, I9II ; read before THE INSTITUTION March 23, I9II ; and before the MANCHESTER LOCAL SECTION March 2I, I9II.)

\section{Summary of Contents.}

General.-Nomenclature. Importance of accuracy. Classification of meters.

Direct-CuRREnt Meters.-Ampere-hour versus watt-hour.

Types of Ampere-hour Meters.-Mercury motor type. Commutator type. Electrolytic meters.

Watt-hour Meters.-Motor meters. Clock meters. The Aron meter. Total current and shunted Aron meters. Mercury meters. Shunts to mercury meters.

Tramcar Meters.

Alternating-Current Meters.-Dynamometer and induction types. Torque of induction meters. Polyphase meters.

Permanent Magnets.

Meter Testing.-Two-circuit connections for testing. Apparatus for generating alternating current. Frequency regulation. Phaseadjusting devices and adjustment for power factor.

RESUlTS OF TESTS.-On alternating-current induction meters. Effect of wave-form. Testing polyphase meters. Interaction of elements of polyphase metcrs. Extra braking torque in induction polyphase meters when both elements are loaded.

Under the title of "Electricity Meters" only such meters are to be understood as are used for the measurement of electrical energy. It is unfortunately a fact that these meters are frequently misnamed; for instance, it is a common mistake to speak of an electricity meter as a "wattmeter," thus making confusion between the units of power and energy. Electricity meters will therefore be considered as watt-time or Joule meters.

There can be no doubt as to the importance of the subject, although meters are frequently a neglected item of an electricity supply department's equipment. As a rule, they are rarely overhauled, and on some systems never even tested; the result being that although such importance is attached to the last half of $\mathrm{I}$ per cent. efficiency 
in the stations, at least 5 per cent. may be lost in distribution, due to defective meters. Consequently it pays to test meters properly before fixing, and also at regular intervals afterwards.

Most of the well-known makes of meters, if properly adjusted and carefully fixed, may be relied upon for about five years; but after that time it certainly pays to have them brought in for thorough overhauling and recalibration. Old meters, after careful repairing and recalibrating, are frequently better than when new, and the cost of the work, if carried out in a properly equipped meter department, is comparatively slight.

In the case of large power consumers, where the conditions of supply justify a low rate per unit being charged, an error of 2 or 3 per cent. on the meter reading may make all the difference between a profit and a loss. Extreme accuracy is therefore essential, and it is always advisable in such cases to install duplicate meters, as greater accuracy can then be obtained, and a further advantage is that it is always possible to remove one meter for testing, when necessary, without having to leave the supply unmetered, or having to fix a temporary meter.

\section{CLASSIFICATION OF METERS.}

Electricity meters may be grouped into three main classes :-

x. Meters suitable for direct current only.

2. Meters suitable for alternating current only.

3. Meters suitable for direct and alternating current.

Each of these groups has its sub-divisions, of which particulars are given later.

\section{Direct-CuRrent Meters.}

Direct-current meters may be either of the ampere-hour or the watt-hour type. Most ampere-hour and a few of the watt-hour meters belong to the first class named above. The remaining types of directcurrent watt-hour meters belong to the third class, and may, as a rule, with occasional slight modifications, be used for measuring the energy in alternating-current circuits.

Ampere-hour versus Watt-hour Meters.-Various claims are put forward on behalf of both ampere-hour meters and watt-hour meters. A brief comparison of the advantages and disadvantages of these types may therefore not be out of place.

The watt-hour type of meter is, if correct, a true energy meter, i.e., it measures correctly the electrical energy in a circuit, independently of variation (within reasonable limits) in any of the three factors (volts, amperes, hours) involved in the quantity measured.

The authors are therefore of the opinion that this is the only type of meter which should be legally recognised as a measurer of electrical energy, although, at the same time, they quite realise the advantages of ampere-hour meters. 
The ampere-hour type of meter can only measure energy correctly on the assumption that one of the factors-viz., voltage-is a constant, and the authors hope that the discussion may throw some light on the justification for this assumption. In addition to measuring the true energy in a circuit, watt-hour meters also possess the advantage that they may be made to start with extremely small currents, owing to the fact that they may be compounded to correct for friction losses, etc. ; whereas in most cases it would not be either convenient or legitimate so to compound an ampere-hour meter.

One of the principal arguments raised in favour of ampere-hour meters as against watt-hour meters is the supposed enormous shunt or pressure circuit losses. On investigation it will be found that these losses have been greatly exaggerated, and, as a matter of fact, are frequently exceeded by losses of much greater importance where amperehour meters are used. The pressure circuit loss in a watt-hour meter is very small, and, moreover, has a load factor of roo per cent., so that the revenue loss to the station has to be reckoned on the lowest possible basis, and will, therefore, in any case, hardly exceed $\frac{1}{4} \mathrm{~d}$. per unit. Now, ampere-hour meters also have their losses, although the fact is frequently unsuspected, and, in this case, the conditions are far more unfavourablc. Presumably every station engineer endeavours to maintain a fairly reliable supply pressure, and with this end in view usually runs with a pressure on the distributors rather over, than under, the declared value, probably to the extent of 2 per cent. at least. Meters of the ampere-hour type, however, must be calibrated for the declared pressure, and it follows that 2 per cent. or more of the revenue is lost, and the greatest loss is naturally at the time of peak load, when the cost per unit is at its maximum.

As an example, take the case of a ro-ampere 200-volt meter; the shunt losses in one of the watt-hour type would not exceed 4 watts, and at $\frac{7}{4} \mathrm{~d}$. per unit this amounts to $8 \frac{3}{4} \mathrm{~d}$. per annum, the corresponding loss to the station with an ampere-hour meter, assuming an average load equal to a half of full load for $\mathrm{I} \frac{1}{2}$ hours per day, would be equal to 2 per cent. on, say, 247 units, which, at $3 \frac{1}{2} \mathrm{~d}$. per unit, is equal to $3 \mathrm{~s}$. $2 \mathrm{~d}$. per annum. The difference between these two amounts is sufficient to allow for a smaller number of units used, lower percentage excess pressure, and higher running costs, and yet show an advantage in favour of the watt-hour meter. If the station engineer runs below the declared pressure, then, of course, the conditions are reversed.

Although it has been stated that watt-hour meters are the better type as regards the correctness of their measurements, it must nevertheless be admitted that ampere-hour meters possess many advantages and, in some cases, are undoubtedly more suitable for the particular conditions obtaining. They are certainly much simpler to test and install than watt-hour meters, and, as a rule, easier to repair and less liable to get out of order ; the price is also much below that of the watthour type.

In England it has been the more frequent practice to use ampere- 
hour meters, whereas on the Continent watt-hour meters were used exclusively up to two or three years ago, and this is still the standard practice in America.

Ampere-hour meters of a particular type were introduced on the Continent a few years ago, but with indifferent success, probably owing to the type of meter used. Quite recently, however, the mercury type of meter has been tried, and so far presumably with successful results.

\section{Types of AMPERE-Hour Meters.}

The three main types are : the mercury motor, commutator motor, and the electrolytic.

Mercury Motor Types.-The mercury motor meter may, so far as English practice is concerned, be justly regarded as the survival of the fittest ; probably 80 per cent. of the direct-current meters used in this country belong to this class, and represent the output of two firms that have had extensive experience with this type of meter.

These meters are thoroughly strong and robust in construction, the workmanship is rather rough, but sufficiently finished where essential.

The accuracy is reasonably good, and they are fairly easy to adjust and calibrate, and, as might be expected from their construction, repair work is comparatively simple. The greatest objections to this type of meter are :-

The impossibility of maintaining a sufficiently high driving torque as the current-carrying capacity is reduced (a very important point now that the average size of meter is falling); this, of coursc, is owing to the fact that the factor represented by the magnetic field is a constant, and to the impossibility of increasing the ampere-turns as the current is reduced.

Troubles Due to the Use of Mercury.-Mercury troubles are necessarily an inherent defect of the type, and vary to a great extent according to the size of the meter, the nature of the load, and local conditions generally.

The most frequent forms of mercury trouble are amalgamation, and what appears to be a gradual disintegration or oxidation of the mercury.

Amalgamation is, as a rule, most pronounced in the armatures, and it appears to be only a matter of time before even the best protected armature is attacked; but the action can be prevented for several years by careful platinising and enamelling. The old covered armatures made by one firm several years ago have been found in good condition after nine years' use.

The disintegration trouble when very bad results in the complete conversion of the mercury to a grey powder.: This effect is only properly observable in shunted meters, as otherwise the circuit would be broken, and the meter badly damaged before the state of complete disintegration had been attained. 
Meters in which a comparatively large current is taken through the mercury chamber (say 50 to Ioo amperes) are subject to another peculiar effect which appears to be partly, if not entirely, of an electrolytic nature, the copper of the positive electrode or anode being taken into solution and deposited at the negative electrode or cathode.

Mercury meters have undergone considerable modification in detail during the last year or two, but all are based more or less on the original "Hookham" models.

A comparatively new meter of this class is constructed on lines quite contrary to the experience of the older manufacturers. The more startling innovations are : an extremely small air-gap, the use of an amalgamated armature, and the absence of any compensation for mercury friction. This design is only permissible on the assumption that the copper and mercury used are both chemically pure, and whether this condition can be satisfied on a practical and commercial scale, is open to considerable doubt; but even if pure when first put into the meters, the mercury must sooner or later become impure when in contact with an atmosphere such as that of Manchester.

It was at one time customary to make mercury meters up to a current capacity of roo amperes with the whole of the current passing through the bath ; in fact, one of the authors has had experience with a total current type of meter intended to carry 500 amperes, but it is now usual to shunt all sizes above 50 amperes, and some makers shunt above Io amperes or even less.

Shunting has the additional advantage of reducing the somewhat considerable temperature error; but errors on fluctuating loads may be introduced unless the inductances of the shunt and bath circuits are balanced.

Commutator Type Ampere-hour Meters.-This type of meter is of Continental origin, and has been on the market for about twelve years; its defects are, however, gradually becoming recognised, and it is therefore probable that it may eventually be superseded by a superior type.

Apparently introduced to meet the demand for an inexpensive meter, in place of the costly watt-hour type, it has created a considerable demand for ampere-hour meters, and, as a result, the previously banned mercury meters now have an extensive sale on the Continent.

This class includes all meters in which a wound armature connected in parallel with a low resistance shunt rotates in the field of a permanent magnet.

The only advantage of this type is that the torque may be maintained practically constant independently of the rated current-carrying capacity, as owing to the extremely small current taken by the armatures, and the use of a shunt, the potential difference on the armature terminals may be adjusted to any desired value (within the limits of permissible voltage drop) irrespective of the current rating.

The armatures are, as a rule, flat, but in one or two cases cylindrical, and, with about one exception, are all wound on metal formers; so that 
they are magnetically damped by the eddy currents generated in the disc or cylinders on which the coils are wound.

The theory of the undamped meter is based on the law of a perfect motor; but as armature resistance and friction are not eliminated, the curve of accuracy is bound to fall rapidly on the low loads. The speed of this type is also exceptionally high.

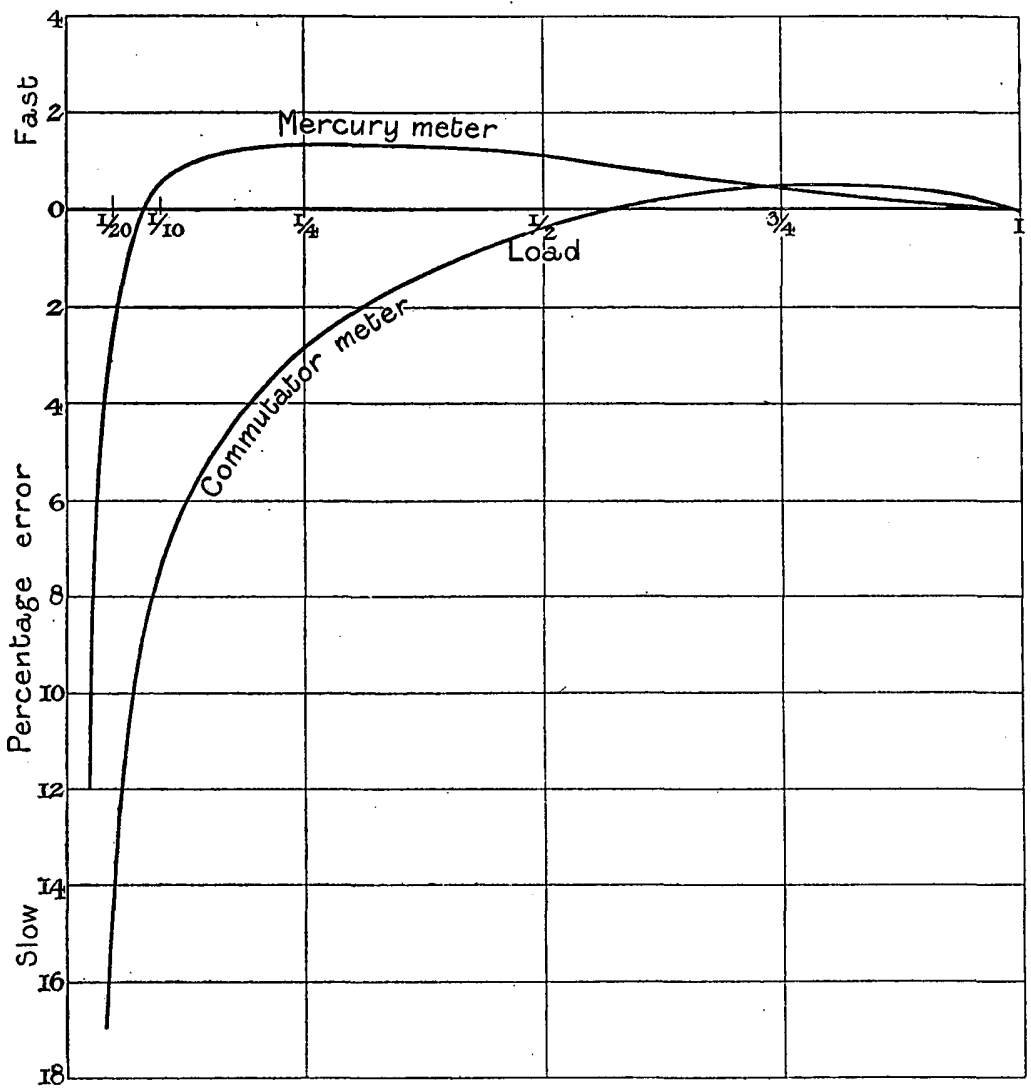

FIG. I

The damped type of meter has a more moderate speed than the undamped type, but requires a higher working voltage across the armature ; it is also more susceptible to changes in brush position and contact resistance, for which the only cure is increased voltage drop. The automatic brush-rocking devices, intended to overcome these troubles, have only been partly successful, and, at the same time, are open to the objections that they complicate the construction, reduce the reliability, and increase the price. 
The usual drop in the shunt is from $I$ to $I^{\circ} 5$ volts at full load.

The general construction is, as a rule, rather flimsy.

The torque may be very high, but is, of course, obtained at the expense of voltage drop.

The two curves in Fig. I have been plotted from the mean results of a large number of tests on different makes of meters, and are characteristic of the mercury motor and commutator types respectively.

\section{Electrolytic Meters.}

These meters necessarily belong to the ampere-hour variety (claims have recently been made for a watt-hour electrolytic meter), but otherwise constitute a distinct class.

In the opinion of the authors, the disadvantages of electrolytic meters so completely outweigh the advantages, that they can hardly be regarded as cheap, even at the present low prices.

Low price is probably the chief advantage claimed on behalf of electrolytic meters; but first cost is only of secondary importance, and it is essential that full consideration should be given to the questions of life, and the possibilities of easy repair and recalibration. A well. made motor meter should be equal to, if not better than new, when repaired, etc., after five years' work, and, moreover, the cost of putting it into good condition is trifling, but the same can hardly be said for meters of the electrolytic type.

It has been stated that these meters are dead accurate on all loads, even down to I per cent. or less of full load; but the experience of the authors does not substantiate this, since it has been found by direct comparison that reliable motor meters are more accurate than electrolytic meters on the higher loads, and quite as accurate on the very low loads.

Admitting the low price to be an advantage, the following are a few of the disadvantages of electrolytic meters generally :-

(a) Delicate and unmechanical construction.

(b) Impossibility of reasonable repair.

(c) Difficulty and expense of testing under working conditions.

(d) High voltage drop.

(e) Difficulty of correct reading.

$(f)$ Difficulty of correct resetting.

$(g)$ Destruction of record by resetting.

(h) No check on "set-up " or " removal" readings.

(i) Many are dirty and messy in operation.

(j) Life certain to be short, and cost of renewals probably 5o per cent. of initial cost of meter.

In the authors' opinion, the destruction of the record is a very serious matter, and the registering device in all meters should be a continuous one. Where dials are provided the registration must of necessity pass through zero once in 10,000 or more units, but there is 
never any doubt as to the number of units used if the correct sequence of figures is observed from the periodic readings.

The only electrolytic meters that have come into extensive use are the "Bastian" and the "Reason."

The former is necessarily a total current meter, and is of the water decomposition type. It has an abnormal voltage drop (about 3 volts at full load), and requires periodic refilling. If working for prolonged periods at loads approaching the rated maximum, errors may be introduced due to evaporation. Correct reading of the scale is difficult after the meter has been in use for any length of time, and practically impossible when the current is passing through the meter.

The "Reason" meter is a shunted one, and has a drop of I volt at full load. It belongs to the metal deposition class, and requires no renewal of electrolyte or electrodes; the metal deposited is mercury, and can, by suitable tipping arrangements, be used over and over again, presumably without any chemical changes taking place in the solution.

The meter is very fragile, and by no means easy to re-set properly. Repairs are expensive, and should they become' a frequent necessity, will be fatal to the success of the meter; the present design, in the authors' opinion, suffers from the disadvantage that in order to fix the meter it is necessary for the fixer to expose the delicate interior, and, moreover, work with his screwdriver in immediate proximity to a slender glass tube.

It is the authors' opinion that all meters should be so constructed that they may be both read and sealed (with the exception of the terminals box) by the testing authority before issue.

Apart from purely mechanical breakages, the most frequent source of trouble appears to be due to leakage of the electrolyte between the glass and the platinum leading-in wires at the sides of the main electrolytic cell.

Several meters have been constructed which depend for their action on the deposition of copper, but such examples as the authors have examined were not worth serious consideration.

\section{Wate-HOUR Meters.}

As stated previously, these are the only true energy meters.

Most good direct-current watt-hour meters are, with slight modification, equally suitable for alternating-current working, but alternatingcurrent meters are not necessarily suitable for direct current, as many of them depend for their action on the principle of the induction motor.

Direct-current Watt-hour Meters.-With one or two well-known exceptions, these are all of the true dynamometer type, and usually have rotating or oscillating volt-component coils. A notable exception is the Aron clock meter, in which the volt-component coils are fixed on the ends of two clock pendulums swinging in the magnetic field of the current-component coils ; this arrangement is reversed in the latest shunted type of meter.

The most general form of dynamometer watt-hour meter consists 
of an armature-which may have either an open, or a closed circuit winding-revolving in the magnetic field produced by one or more coils carrying the main current. The well-known Elihu Thomson meter was the prototype of this class. The mechanical friction is usually counterbalanced by a slight torque due to the magnetic field of a small coil placed in series with the armature; although this compensating torque varies as the square of the voltage applied to the meter, it is sufficiently constant for all practical purposes. In one wellknown modification of the revolving armature type of meter, the armature, instead of revolving, merely oscillates through an angle of about $30^{\circ}$. The use of a commutator is therefore unnecessary, as the armature need only consist of a single coil ; the shunt circuit is never completely interrupted, but the current through the armature is periodically reversed by an ingenious combination of an electrically operated two-way switch and a potential resistance. As the connection between the oscillating spindle and the counting train is purely electrical, the latter may be fixed at any reasonable distance from the meter.

An electromagnctic device for operating the counting train has been employed by a well-known English firm of instrument makers, the object, of course, being to eliminate the friction due to the counter, etc., by operating the train from an independent electrical source of energy, instead of from the operating portions of the meter.

The chief objection to the electro-mechanical operation of the counting train is the necessity for employing ratchet gears. A thoroughly reliable pawl and ratchet gear, suitable for this class of work, is by no means an easy thing to design. The adjustment also requires great care, in order to avoid errors due to slip, resulting from the spring and inertia of the moving parts.

The oscillating type of meter is naturally somewhat complicated, and faults are rather difficult to locate, but apart from these objections, meters of this type are remarkably accurate, and as they are usually well made, the accuracy is maintained over long periods, unless there is any change in the strength of the permanent magnets.

These meters are not suitable for use on alternating-current circuits.

The simple revolving armature type of dynamometer watt-hour meter with closed circuit armature has many good features, and if properly designed, and sold at a reasonable price, should be a serious rival to the mercury motor ampere-hour meter. The authors therefore consider that there is a large future for this class of meter.

The main sources of trouble in practice with dynamometer type watt-hour meters, are :-

Commutation.

Brushes.

Permanent brake magnets.

Bottom bearing.

Cramped design. 
The small diameter commutators so frequently used appear to the authors to be very unsuitable, and probably better results are obtained with robust commutators having a greater number of segments, connected to multi-coil armatures of fairly large diameter. In the case of one well-known type, the meters are fitted with easily removable commutators, and the general details of the arrangement appear to be very good, but there is always the possibility of altering the relative position of commutator segments and armature coils, with a resulting alteration in the calibration of the meter. Unless they actually break circuit, which should, of course, be impossible, there appears to be no reason why the brushes should cause sparking on the commutator; probably the best forms of brushes are those making a number of separate and independent contacts, the pressure of the brushes on the commutator being controlled by special springs, and not dependent in any way on the natural springiness of the brushes themselves.

Bottom, or footstep bearings, are a frequent source of trouble. Owing to the comparatively heavy weight of the rotating portion of the meter, it is essential that this bearing should be very well made; only the finest jewels should be used, and experience. would appear to show that a rounded or spherical-ended shaft is to be preferred rather than a pointed one. There appears to be scope for the design of a reliable ball-bearing for this purpose.

The removable spindle tips used by one well-known firm are a distinct advance.

The cramped design of these meters is responsible for most of the troubles in connection with the initial calibration, and also the permanency of the calibration, since permanent magnets will not withstand the severe conditions which it imposes.

When great accuracy is required, it is necessary for this type of meter to be wound astatically, and for certain working conditions it is in any case absolutely essential. Within the limits of ordinary house-service accuracy requirements, this special and expensive form of winding is not necessary, and where the local conditions necessitate the use of astatic meters, it is better to use the type referred to below.

\section{Clock Meters.}

The well-known Aron meter is the only one that will be referred to, as there are not, so far as the authors are aware, any other reliable meters of this type in use.

This meter is probably the most complicated (mechanically) and, at the same time, most accurate and reliable watt-hour meter made; it is a true dynamometer, and may, with slight alteration, be used for a wide range of measurements, both direct and alternating, and on either simple or multi-wire circuits. The principle of these meters depends upon the differential action of two clocks which are driven by a common main spring, electrically wound. The escapement train of each clock is connected to a common spindle through a suitable differential gear, the 
common spindle being further connected in a special manner to the ordinary integrating dials.

The differential gearing is so arranged that as long as both clock trains are running down at the same rate, there is no rotation of the common spindle. This condition, however, is not attained when both pendulums are swinging with the same periodicity, since in order to avoid resonance effects, the wheel gearing one train to the differential has one more tooth than the corresponding wheel of the other train.

The pendulum bobs of the two clocks are formed of coils into which the current is led by suitable flexible connections, and these coils swing in the immediate vicinity of other fixed coils. The resulting magnetic reaction between the fixed and movable coils causes a variation in the relative periodicity of the two pendulums, and consequently in the rate at which the two clocks run down.

There are several patterns of the Aron meter, but the main differences between these are the methods of connecting the pendulum coils. The direct-current total-current type, and all alternating-current meters have the pendulum coils in the volt or pressure circuit, whereas in the direct-current shunted type, the pendulum coils carry a portion of the line current. The shunted type of meter cannot be used on alternating-current circuits,

Advantages of Aron Meters.-True watt-hour meters.

Astatic, and therefore not affected by stray fields. (This is not strictly correct in the case of polyphase meters, for the currents in the pendulum coils differ in phase by $120^{\circ}$. It therefore follows that stray alternating magnetic fields may affect the pendulums to an unequal extent ; but in practice errors in registration due to this cause are hardly noticeable. Polyphase meters are not affected by unidirectional fields, or even by alternating fields having a periodicity differing from that of the meter circuit.)

Contain no iron or permanent magnets. (In the direct-current shunted type the volt coil flux is concentrated by means of laminated iron stampings forming a definite magnetic path.)

Not affected by momentary overloads or short circuits.

Temperature error, except in the shunted type, practically nil. time.

Accuracy practically constant at all loads and for long periods of

As a rule, some very definite indication is given when the meter is out of order, and it is very unusual for a gradual increase, or decrease, in the registration to develop, as is frequently the case with motor meters.

In the event of any slight mechanical fault developing, it is possible to remove the clockwork for the purpose of adjustment, and afterwards replace it without interfering with the calibration of the meter.

Disadvantages.-Testing is both difficult and tedious, and unless extreme care is taken with the tests, inconsistent results are obtained.

It is impossible to make a rapid time test at any particular load, or 
even to ascertain quickly whether the meter is working approximately correctly, unless the load is a fairly heavy one.

It is very difficult to avoid a slight creep, either forward or backward, which may cause apparently considerable errors, when working either on very low loads'or with long intervals on open circuit.

It is essential that the meters should be fixed perfectly plumb, and if mounted on wooden boards, trouble may arise due to the warping or shrinking of the wood.

Poor insulation of the commutator; this occasionally results in carbonisation and partial shunting of the pendulum coils, the meter then registering slow.

Pitting of the Pendulum Arbor Pivots.-This is a particular and rather frequent source of trouble. It appears to be due to chemical or electrochemical action, and is occasionally very marked, the pivots being reduced to less than a half of their original diameter. The action is confined entirely to the back ends of the arbors, and although it may, to a certain extent, be accelerated by the immediate proximity of the pendulum coil leading-in wires, it is doubtful if these are the primary cause of the trouble. A more likely explanation is chemical action caused by the vulcanised fibre blocks used for insulating the terminals of the pendulum leading-in wires. The insulation of the winding gears occasionally breaks down, due to the same cause. The experience of the authors leads them to consider any form of vulcanised fibre to be unsuitable for use in the construction of meters and instruments, etc.

Owing to the somewhat complex details, very careful construction and adjustment are necessary, or otherwise mechanical faults are apt to develop.

The location of faults is rather a difficult matter, and repairs are expensive, owing to the skilled workmanship required. The houseservice type of meter is rather bulky, and not at all convenient for many situations, and the price is also a deterrent to the use of these meters for small installations.

\section{Total-current and Shunted Direct-current Aron Meters.}

The total-current type is the only one suitable for house-service conditions, and is the best type for station work up to about 2,000 amperes. Above this size the use of the shunted type is quite legitimate, provided that the necessary precautions are taken.

The advantages of the shunted type are:-

Connections are much simplified, as the shunts may be joined in circuit at any convenient place, and connected to the meter by means of comparatively small leads. Severe mechanical strains on the meter. are also avoided.

The meter may be removed for testing or adjustment without disturbing the station circuits.

If the resistance of the shunt is carefully measured, the meter may be tested with a small current on a shunt of higher resistance giving 
the necessary voltage drop, and by this means, long time tests may be conducted in the test-room with great accuracy and ease, and with quite a small expenditure of energy.

The disadvantage of the shunted type are :-

The relatively high temperature coefficient, which is about $0^{\circ} \mathrm{I} 3$ per cent. per deg. F.

The possibility of error due to the various contacts in the pendulum circuit working loose. There are about twenty-four clamped connections in a meter, and as the drop on the shunt at full load is only 0.2 voilt, troubles due to bad contacts are only a matter of time, and are much accelerated by the temperature variations and vibrations encountered in a generating station. Experience has proved that for reliable working it is absolutely essential that most, if not all, of these connections should be soldered; neglect of this precaution means that the meter will gradually register slower, no matter how carefully calibrated.

After considerable experience with most makes of watt-hour meters, the authors consider that a type free from permanent magnets, such as the Aron meter, is the only type capable of withstanding the severe conditions which exist in large direct-current generating stations. Overloads and external magnetic fields are sufficient to destroy calibration of all meters containing permanent magnets.

Mercury Type Watt-hour Meters.-There are not many watt-hour meters of any note in which mercury is used. Mercury is a necessary evil in certain successful types of ampere-hour meters, but its use in watt-hour meters is, in the opinion of the authors, very undesirable. Their experience is that this type of meter is very unreliable, and that the mercury troubles appear to be more pronounced than in the ampere-hour type. Most mercury watt-hour meters are shunted, and many calibration errors are no doubt traceable to this fact.

\section{Shunts to Mercury Meters.}

As previously stated, it was usual, up to a few years ago, to construct mercury motor type ampere-hour meters to carry the full current of the circuit through the mercury bath in all sizes below 100 amperes; and occasionally in even larger sizes. It is now usual to shunt the mercury bath for currents of very much lower value, one firm shunting even the 5-ampere meters, the shunt, in this instance, providing the only means for adjusting and calibrating the meters. It is open to question whether the use of these shunts is desirable, and it seems probable that any slight advantage gained by their use is outweighed by the attendant disadvantages.

The possible advantages are :-

(a) Reduced temperature error.

(b) Less liability to damage through momentary overloads and short circuits. 
(c) Circuit not opened in case of mercury chamber becoming empty.

(d) Possibility of using a smaller and lighter armature, with a correspondingly smaller air-gap, and reduced speed.

The main disadvantages are :-

Liability of considerable error due to change in mercury resistance; the mercury bath is in parallel with a solid metal shunt of practically constant resistance (neglecting temperature coefficient), whereas it appears to be very probable that the resistance of the mercury bath may be a very variable quantity.

Item $(c)$ above, while an advantage in one sense, is also a disadvantage, as the meter may be gradually slowing down, due to oxidation or leakage of the mercury, without any external evidence of the fact.

The danger of serious changes in the calibration due to variation in contact resistance between the shunt and the bath circuits.

Speaking generally, it may be safely said that shunts are always more or less undesirable on any type of meter, but particularly on service meters; and their use should be avoided as much as possible for all meters not exceeding $\mathrm{I}, 000$ amperes current capacity.

\section{Tramcar Meters.}

The use of meters on tramcars has been much discussed during the last year or two, and many tramway departments have been experimenting with a comparatively small number of meters. So far, however, little has been said as to the existence, or otherwise, of a meter suitable for this particular class of work. The authors' experience leads them to form the definite opinion that there is not, at the present time, on the market, a meter capable of withstanding for any length of time the severe conditions obtaining on a tramcar.

That these conditions are exceptionally severe is sufficiently proved by the condition of meters that come into the test-room for checking (and usually repairing), after having been in commission for comparatively short periods.

Commutator type watt-hour meters are not suitable for car work, partly owing to the weight of the moving parts and the short life of the bottom bearing, and also owing to the violent sparking on the commutator caused by the excessive vibration. Owing to the lightness of their revolving parts, and the cushioning effect of the mercury, there is no doubt that the mercury motor ampere-hour type of meter gives the best results for this class of work. At present, however, the enormous momentary overloads, and the excessive vibration, are quite sufficient to alter the strength of any permanent magnets, and even when a very large proportion of the current is shunted, the life of the mercury is very short. The shunting also causes considerable inaccuracies, as the meter gives no indication of not working properly long after the accuracy has completely disappeared. 
Whether any material benefit is derived from the use of meters on cars is a very controversial question, and quite outside the scope of this paper.

\section{Alternating-Current Meters.}

These may be sub-divided into "dynamometer" and "induction" types. The dynamometer type is, as a rule, suitable for alternatingand direct-current circuits, but the induction type probably represents at least 75 per cent. of the total sales of alternating-current meters.

The commutator type of dynamometer meter is suitable for alternating-current circuits, and should be capable of development as a standard type, but the error on low power factors is, as a rule, rather considerable on the low-voltage ranges, owing to the high inductance of the armatures, unless neutralised by eddy currents. This is rather a serious matter in the case of roo-volt meters working off the secondaries of pressure transformers.

The Aron meter is perhaps the best example of a universal dynamometer watt-hour meter. Owing to the high resistance of the pressure circuit, and the relatively large proportion which is noninductive, the error on low power factors is not very great although, as might be expected, the meter has a tendency to register fast on lagging current loads, unless eddy currents are present, in which case it may actually register slow. Experiments have shown that this meter can be used on any frequency and wave-form, the only portion requiring any special adjustment for different frequencies being the winding gear.

For station work and heavy service conditions, where accuracy and reliability are essential, the dynamometer types of meter are to be recommended, but for ordinary service work, or even on switchboards, the induction type is now almost universally used. Induction meters have the great advantages of small size, lightness, cheapness, ease of adjustment, and fairly constant calibration, provided that the strength of the permanent brake magnets does not vary to any appreciable extent.

The shunt, or volt coil losses, in the induction meter are very much lower than in the dynamometer type, but this is mainly due to the extremely low power factor of the coil circuits, and probably also to the fact that, as a rule, the whole of the pressure circuit consists of active turns, whereas in the case of dynamometer meters a large portion of the pressure circuit is merely dead resistance.

The great objections to the induction type are, the small driving torque and the variation in accuracy with varying wave-form. In several recent designs, however, the torque has been considerably increased.

For any particular wave-form and frequency, the quadrature may be very accurately adjusted, and, moreover, if necessary, this adjustment may be effected in conjunction with a current transformer.

The temperature error is comparatively small, since both driving and brake torques are due to eddy currents generated in the same armature.

VoL. 47. 
Torque of Induction Meters.-Endeavours are now being made to obtain a maximum driving torque with a minimum shunt coil loss. This is quite right in moderation, but there is a danger of its being overdone. Shunt losses are reduced by the use of a leakage field instead of a direct field for the driving component of the volt flux ; consequently the meters are more susceptible to magnetic disturbances. In the case of polyphase meters the accuracy is also seriously affected.

It is questionable whether there is any advantage to be gained by pushing the torque beyond the limits necessary for swamiping the friction errors, since if the speed is to to be kept within reasonable limits, it will be necessary to increase the strength or number of the brake magnets.

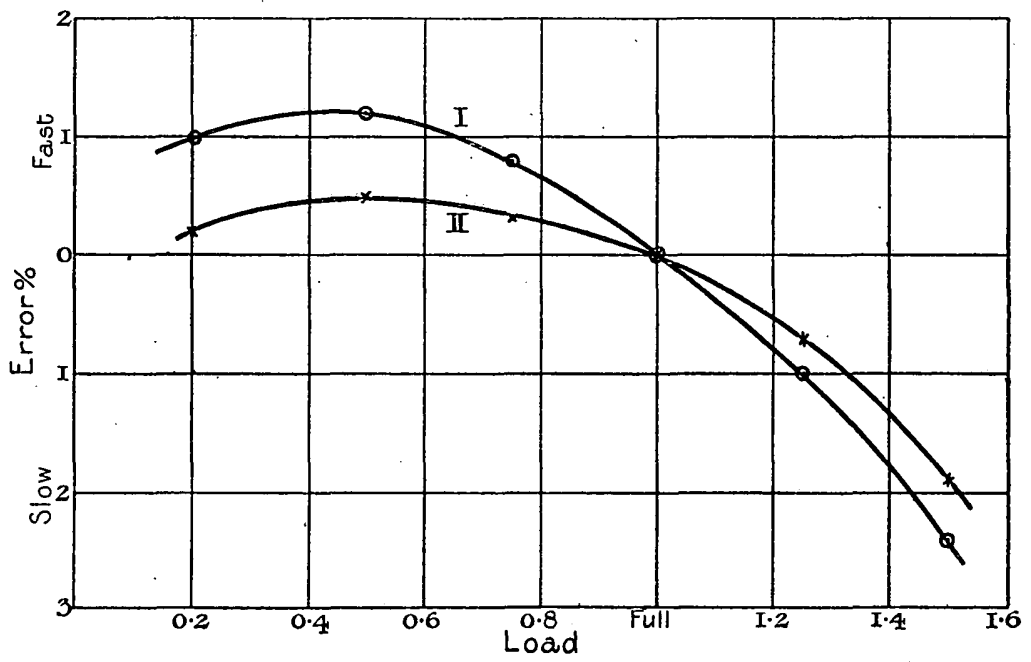

FIG. 2.

The driving torque, and, to a corresponding extent, the brake torque, may be increased by increasing the size and thickness of the disc or armature, but this means a heavy rotating part with a proportional increase in the wear and tear. Probably the better method is to increase the driving fluxes, and balance the increase torque by means of a stronger braking system, so as to maintain a fairly low speed; a more uniformly horizontal curve of accuracy will then be obtained.

Fig. 2 shows two curves characteristic of induction type meters. The rapid falling off in the speed of the meter at the overloads is due to the fact that the driving fluxes also act as braking fluxes, and the effect becomes very appreciable at the higher loads because this brake torque increases as the square of the fluxes. The two curves are plotted from observations made on the same single-phase meter. Curve I. was 
obtained by adjusting the permanent brake magnet so that a minimum braking effect was produced, and the speed of the meter at full load was then about 50 revs. per minute. Curve II. was obtained by adjusting the magnet so that the maximum braking effect was produced, and the speed of the meter at full load was about 30 revs. per minute. It is seen that the motor gives a more uniform curve of accuracy when the braking effect of the permanent magnet is increased. It may be mentioned that in plotting the curves the meter was assumed to have no error at full load in both cases.

Alternating-current meters are essentially of the watt-hour type. The suggestion * has been made that an alternating-current amperehour meter might be desirable for the purpose of penalising consumers on whose circuits the power factor is very low. Apart from the reasonableness or otherwise of this suggestion, which is outside the scope of this paper, there are many difficulties in connection with the manufacture of a reliable alternating-current ampere-hour meter, and, moreover, it is a comparatively easy matter so to calibrate a meter of the watt-hour type that it shall register as fast as may be desired on inductive loads. This result may be obtained on either a dynamometer or an induction meter, by merely shifting the phase of the flux due to the volt circuit coil relatively to the applied voltage.

The best way of making the quadrature adjustment in induction meters is to test the meter with a lagging and a leading power factor, and also at unity, say, $0^{\circ} 5$ lagging, unity, and $0^{\circ} 5$ leading. When the meter has been adjusted until the eiror under these three conditions becomes approximately the same, the quadrature may be regarded as correct, although if checked with an indicating wattmeter of the dynamometer type, it may be found that the meter has a slight creep when the wattmeter reads zero, the explanation of this being the error in the indicating wattmeter caused by the inductance of its pressure circuit. The term "power factor" in the above is intended to represent the ratio $\frac{\text { watts }}{\text { volt-amperes }}$.

Dynamometer meters are unsuitable for working off current transformers if intended to be used on circuits having very low power factors; because the error due to the inductance of the volt coils is intensified by the effect of the lead in the transformers. This error can, to a great extent, be corrected by means of eddy currents induced in suitable closed circuits or masses of metal, or even by.shunting the series coils, but the meter will only then be suitable for one particular frequency, and the accuracy will be affected by changes in temperature and wave-form, etc.

Tests made on a dynamometer meter of a well-known make showed that the eddy currents induced in the metal cover were more than sufficient to counterbalance the inductance of the armature. The meter registered slow on inductive loads with the cover on, and fast when the cover was removed.

* Proceedings of the Institution of Electrical Engineers, vol. 42, p. 616. 
The temperature error in dynamometer meters is, as a rule, fairly high. The primary cause is the variation in resistance of the brake disc, and it is possible that this might be compensated for, to some extent, either by the use of resistance wire having a high positive temperature coefficient in the pressure circuit, or perhaps a better method would be

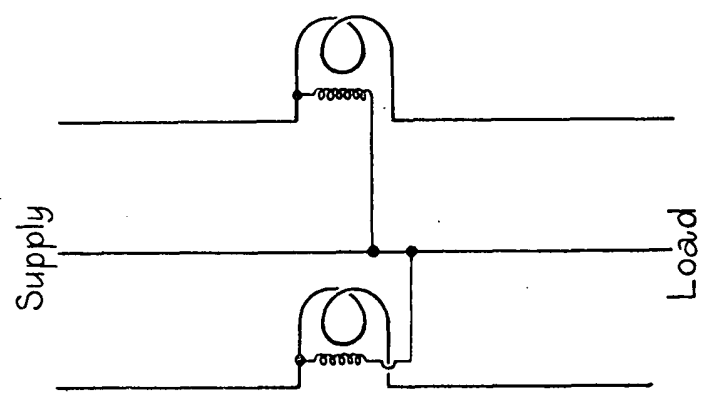

FIG. 3.

to shunt the series coils by a resistance having a negligible temperature coefficient. The shunt method would, of course, have to be used with discretion even for direct-current work, as it is probable that errors might be introduced when working on fluctuating loads, due to want of balance in the inductances of the two circuits. In the case of meters

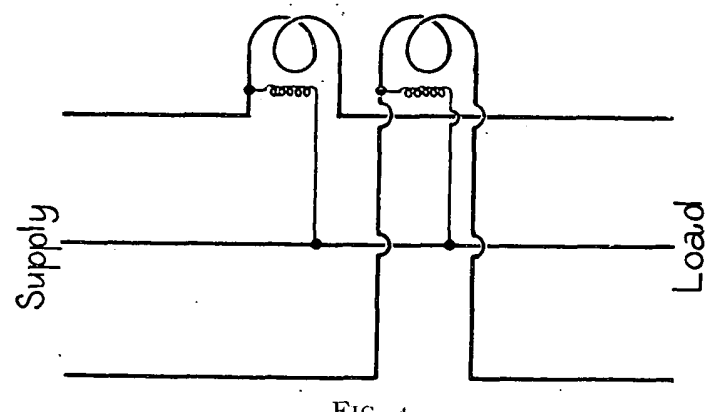

FIG. 4 .

intended for use on alternating-current circuits, it might be possible to apply this method of adjustment to correct for the lag of the volt coil current, and even for the lead in a current transformer.

\section{Polyphase Meteris.}

Polyphase meters are now extensively used for measuring the energy on 3-phase circuits. Many of the so-called polyphase meters 
are only single-phase meters, and their measurement of the 3-phase energy is based on one or more of the following assumptions :-

(a) Sine waves of current and volts.

(b) Exact balance of current on the three phases.

(c) Exact equality of volts between the three phases.

(d) Phase angle of exactly $120^{\circ}$ between phase voltages and between phase currents.

(e) The possibility of creating an artificial neutral or star-point.

$(f)$ The possibility of obtaining a resultant current in phase with the voltage between phases.

In practice the possibility of obtaining any of the above conditions is always open to considerable doubt, and the only reliable meters are those consisting of a combination of two or more single-phase elements, the construction and arrangement of the combination to be such as to admit of being accurately tested on a single-phase circuit.

The only reliable and satisfactory method of measuring the power in a 3-wire 3-phase system under all conditions of load and power factor is the well-known 2-wattmeter method, and the equivalent arrangement of two watt-hour meters is the most satisfactory method of measuring the total amount of electrical energy supplied to a 3-phase 3-wire system. On a 4-wire system three meters are required, or, generally speaking, $(n-\mathrm{I})$ meters where $n=$ number of wires. This rule is applicable to either a direct-current multi-wire system or to an alternating-current system with any number of phases, provided that the minimum number of wires be used.

For convenience and simplicity it is usual for the two necessary watt-hour meters to be contained in the same case and to integrate on a common set of dials, but when used under these conditions it is essential that the requirements of the 2-meter method should still be fulfilled.

Figs. 3 and 4 are the arrangements described above.

* The following set of diagrams (Figs. 5 to 9) show some of the methods in use for metering the energy on so-called balanced 3-phase systems.

Fig. 5 is intended to be the equivalent of connecting the pressure terminal of a single-phase meter to the star-point of a 3-phase system, when the actual neutral is not available. Equality of phase current and phase volts is assumed.

A constant multiplier of 3 will be required in the gearing.

This method is only applicable to meters of the dynamometer type.

Fig. 6 is a modification of the previous arrangement applicable to induction meters, and is generally used in conjunction with a pressure transformer.

A constant multiplier of 2 is necessary in gearing if the meter is calibrated for the line voltage.

Considerable errors may be introduced if the phase voltages are 
not equal, and this is particularly the case when the power factor of the circuit is low.

Fig. 7.-In this case the calibration is based on the fact that in the hypothetical 3 -phase circuit, there is an angle of $30^{\circ}$ between the phase voltage, and the resultant voltage between any two phases.

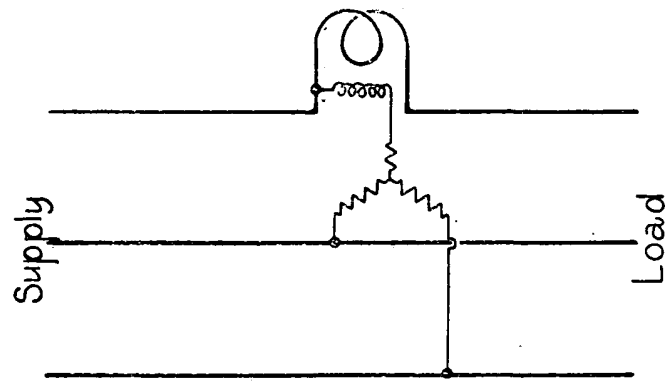

FIG. 5.

And since in an induction type of meter the mean torque is proportional to $\mathrm{F}_{v} \mathrm{~F}_{a} \sin \theta$ where $\theta=$ the angle between the current and volt coil fluxes, the maximum mean torque is therefore attained when $\theta=90^{\circ}$.

In an ordinary single-phase meter this angle exists when the power factor of the circuit is unity, if the quadrature adjustment is correct.

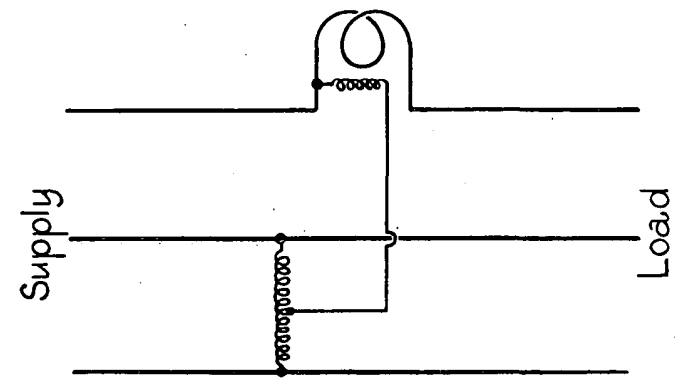

Fig. 6.

In the case of meters arranged for connecting, as in Fig. 7 , the pressure coil flux is arranged to lag $60^{\circ}$ only behind the current flux, when tested on a circuit having unity power factor, and the other $30^{\circ}$ is made up by the angular displacement of the resultant voltage.

Uniformity of phase-voltage, and exactly $120^{\circ}$ displacement between phases are assumed.

The gearing constant is $\sqrt{3}$.

This is, undoubtedly, the worst example of inadmissible connection. 
Not only are the probabilities of error very great (they amount almost to certainties) but the meter, as calibrated, is extremely difficult to test accurately, and it is almost impossible to test it correctly over a very wide range of power factors.

If the free end of the volt circuit is connected to the w'rong phase, which may very easily be done, the meter will only read one-half

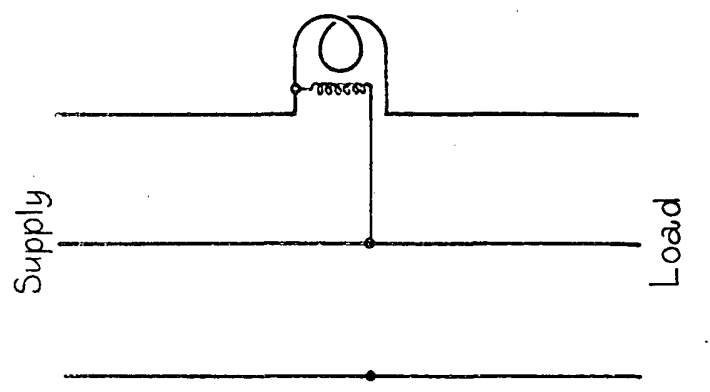

FIG. 7 .

of what it should do, i.e., the angle between the volt and current fluxes will be $60^{\circ}-30^{\circ}=30^{\circ}$ instead of $60^{\circ}+30^{\circ}=90^{\circ}$.

Fig. 8.-This method is based on the assumption that the power in a 3 -phase balanced circuit may be expressed as $\sqrt{3} \cdot \mathrm{V} \cdot \mathrm{A} \cdot \cos \phi \cdot$

The mean torque in the meter is proportional to the product of the volts between any two phases, the vectorial sum of the currents in

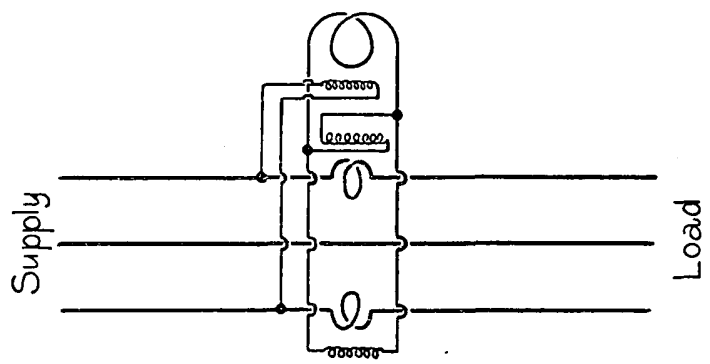

FIG. 8.

the same two phases, and the cosine of the angle between the resultant current and voltage. Since the circuit is assumed to be a balanced one $A=A_{r}=A_{2}$, and the sum $=\sqrt{3} A$. This resultant current is in phase with the resultant voltage between phases when the equivalent power factor of the system is unity. The total power is therefore represented by $\mathrm{V} \times \sqrt{3} \mathrm{~A} \cos \phi$, and the mean torque of the meter is proportional to this quantity. 
24 RATCLIFF \& MOORE : ELECTRICITY METERS [March 23rd,

If used in conjunction with two current transformers, a standard type of meter with only one current coil may be used, but on lowvoltage circuits it would be possible to dispense with the current transformers, if a special duplex winding were provided on the meter; but the transformers form the better arrangement, and, moreover, the

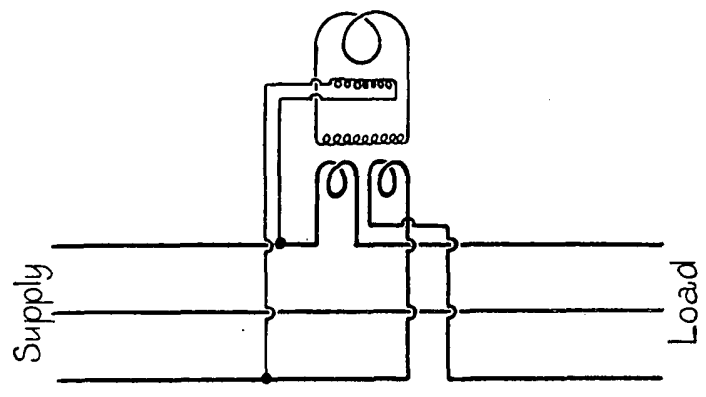

FIG. 9.

meter will read direct without the necessity for a multiplying constant in the gearing.

Equality of current and phase angles are.assumed.

This is probably the best of the various compromise arrangements.

Fig. 9.-This is a special case of the previous example. Instead of

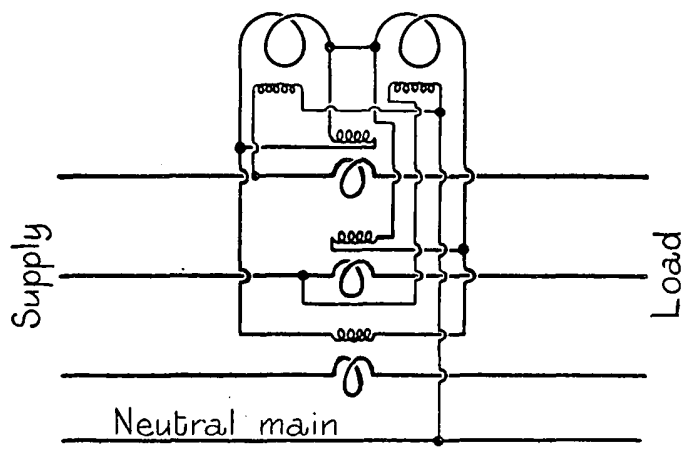

FIG. IO.

superimposing the currents on the coil of the meter, a transformer having one secondary and two primary windings is used. The secondary current is therefore proportional to $\sqrt{3} \mathrm{~A}$, and is in phase with the resultant voltage when the power factor of the system is unity.

Fig. Io shows a method of superimposing the third phase current upon the two meters used for measuring the energy in a 3-phase 4-wire circuit. In this case the volt coils of the meters are connected 
as shown between two of the lines and the star-point instead of between the lines. The fluxes are therefore proportional to the phase voltages, and as the connections of the third current winding are reversed, the volt factor becomes $-\left(v_{\mathrm{r}}+\eta_{2}\right)$, that is $\nu_{3}$.

\section{Permanent Magnets.}

With the exception of the Aron and possibly one other type, all electromechanical meters depend for their action upon the use of permanent magnets. In ampere-hour motor meters, these magnets provide both the driving and the brake torques, and in all motor watthour meters, either direct current or alternating current, they provide the controlling or brake torque.

It will thus be seen that the so-called permanent magnet constitutes a most important feature of practically every type of motor meter, and naturally should therefore be both well made and thoroughly reliable.

There is no comparison between the use of permanent magnets in indicating instruments of the moving-coil type and in integrating meters. In indicating instruments the magnet is usually very long, the air-gap is extremely small, demagnetising influences are comparatively slight, and, further, the readings of the instruments are proportional to the magnet pole strength. But in the case of integrating meters the magnets are often very small, with a correspondingly reduced magnetomotive force ; the local demagnetising influences are of considerable magnitude, and may at times even be abnormal ; and the registrations of the meter are, as a rule, inversely proportional to the square of the pole-strength. Even well-designed magnets of good quality may have their action considerably nullified by the influences of stray magnetic fields, produced by the current in either the coils of the meters or in neighbouring conductors.

It does not appear to be realised how intense may be the magnetic fields produced by the series coils of a meter in case of a short circuit or momentary overload, and consequently the means taken to shield the magnets from the effects of such fields are quite inadequate, and, in some cases, even help to concentrate the action of the stray fields on to the permanent magnets.

If the condition of damaged meters removed "off-circuit" is any criterion, there is no doubt that the overload tests usually specified are not to be regarded as the equivalent of actual service short-circuit conditions.

The effect of local stray fields in large generating stations is enormous, and is far greater than is generally realised. One of the authors has seen a dynamometer watt-hour meter stop at about onethird load, and actually reverse at one-quarter load, due to the effect of a stray field, which was obviously stronger than the field of the meter's own current coil.

As a further instance of the effect of these stray fields, the curve given in Fig. II is very interesting; it represents the varying error in 
the readings of five recording voltmeters which were contained in castiron cases, and it will be noticed that the variations, when plotted, give an almost exact reproduction of what was probably the station load curve at the time.

It will therefore be understood how essential it is that the magnets in station meters should be shielded as completely as possible, and, in addition, the torque-producing portions of the meters should be astatically wound. It is frequently supposed that alternating meters are not affected by stray fields, and this would be true if the stray fields were undirectional and the permanent magnets were efficiently

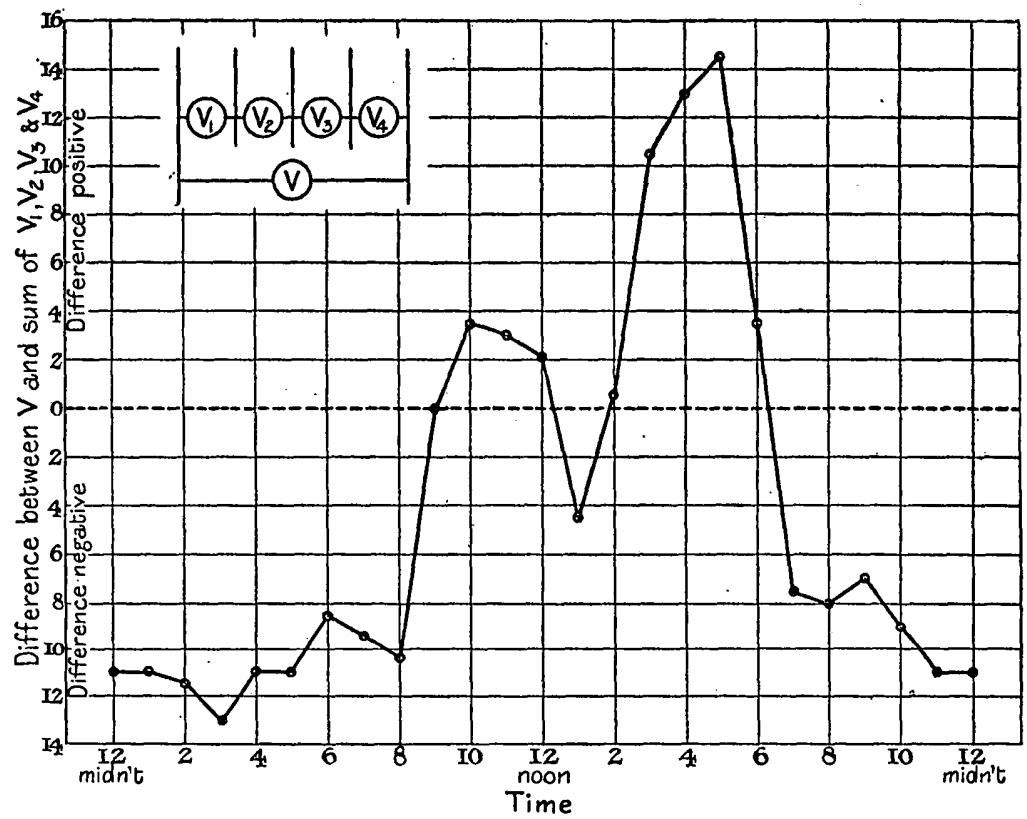

FiG. II.

shielded ; but the fact must not be overlooked that alternating-current meters and instruments may be affected by alternating magnetic fields in synchronism with their own self-induced fields.

This effect is very noticeable on indicating instruments when the frequency of the stray field varies slightly from that produced by the current through the coils of the instrument itself: Under these conditions the pointer will swing over a portion of the scale with a periodicity equal to the difference between the periodicity of the superimposed fields. This effect must also be present in integrating meters under the same conditions, but, of course, is not observable.

Ampere-hour meters are not, as a rule, affected to the same 
extent as watt-hour meters, by variation in the strength of the permanent magnets, since a reduction in the brake torque proportional to the square of the variation in the pole-strength is partly counterbalanced by a reduction of the driving torque proportional to the variations in the pole-strength. This, of course, does not apply to meters in which there are separate magnetic circuits for producing the driving and braking torques respectively.

In contrast to the short magnets previously referred to, are the long magnets now used in the leading types of mercury motor ampere-hour meters. The advantages of having long brake magnets in alternating-current meters is also beginning to be realised.

\section{Meter Testing.}

Mention has previously been made of some of the sources of errors in meters as at present designed. Certain of these errors cannot be wholly eliminated, and are only made negligibly small under specified conditions of working.

It must be remembered that, as a rule, an electricity meter in use has no check on its registrations, it being the sole instrument responsible for the measurement of the energy consumed on its particular circuit. When a man buys a watch for ordinary purposes, he has little need to have it periodically tested, for if any irregularities develop, he is at once made aware of the fact because his watch is not the sole instrument responsible for the measurement of time.

The revenue of an electricity supply undertaking is derived mainly from the registrations of the consumers' meters. This is based on the registered total, and some of the meters may register fast, thus tending to balance those registering slow ; but on a point of equity it is clearly unfair to make one consumer pay for the energy used by another.

In the case of private installations, energy meters become, as a rule, mere switchboard ornaments, in that they are rarely, if ever, tested, and their accuracy is therefore unknown. If it is necessary to instal meters in private installations it must also be necessary to know their accuracy.

Generally speaking, the main objects of having meters tested by testing authorities is to ascertain that the errors of registration are within the legal or specified limits, and that the meters run satisfactorily under load conditions. In certain other cases, when the meters are not used for the measurement of energy supplied to a consumer, but are used for the testing of plant, it is the actual errors or corrections for the meters which have to be determined very exactly, legal or specified limits of error not then being in question.

In the opinion of the authors, no effort on the part of the designers or the manufacturers should be spared to bring the errors down to the lowest possible value. Until a satisfactory, commercial meter can be produced at a reasonable price and having an error not exceeding I per cent. under all reasonable conditions of working, there is room for improvement in design and construction. 
It is, the lauthors consider, distinctly inadvisable and a retrograde step to extend the legal permissible limits of error, unless it can be shown that meters cannot be brought up to this standard. The authors' experience is that meters can be satisfactorily manufactured to even closer limits than the legal specification, and any extension of the limits of error is therefore a temptation to the maluufacturers to relax their efforts for the production of a really accurate meter. Generally speaking, the errors increase after installation, and large initial errors may mean abnormally large errors after continued service. On the other hand, small initial errors are conducive to reasonable accuracy over a considerable period of time.

The following section is confined to that branch of meter testing which consists in the determination of the errors of registration.

All the instruments used for verification purposes should be sub. standards,* and should be verified at frequent and regular intervals by comparison with secondary standards.* It will be obvious that the errors of the sub-standards must be known to within much smaller limits than the limit of error allowed in the meters under test. It is however, not an uncommon experience to find meters being tested with ammeters and voltmeters which can only be relied on to within 2 or 3 per cent., giving a possible error of 4 to 6 per cent. in the product of the readings of the two instruments. Another common mistake is to use the same range on, say, an ammeter, to test the meter at all loads from full load or over, down to $\frac{1}{20}$ load, so that the lower readings are taken. on a very small.length of the ammeter scale. This procedure gives rise to considerable errors of observation at the lower loads independent of the accuracy of the ammeter, and the fact must not be overlooked that it is often of greater importance for the meter to be accurate at $\frac{1}{2}$ or $\frac{1}{4}$ load than at full load. A consumer's meter on a lighting load is probably rarely subjected to full load-conditions.

The connecting up of meters for testing is of considerable importance, especially if the current capacity of the meter is as high as about 300 amperes or more. Most meters have a temperature coefficient, and in some cases this is as high as 0.25 per cent. per deg. F. The temperature of the inside of the meter case, which is the important temperature, depends not only on the outside temperature, but also on the rate of generation of heat in the coils. With watt-hour meters it is generally understood that they have their shunts fully excited for at least an hour before observations are commenced, so that the meter may be properly warmed up. With heavy current meters, however, there is often more heating from the series coils than from the shunt coils, and this becomes quite serious if there are bad contacts in the series coils connections. Much heat is generated at the bad contacts, and this is quickly conveyed to the interior of the meter by the good heat-conducting propertics of the copper. Despite this fact, however, extremely poor connections may often be observed in test-rooms.

* As defined in the Engineering Standards Committee Specification for Ammeters and Voltmeters. 
With heavy current meters it frequently happens that special cable ends are used for the connections to the series coils, in order to get the best possible contacts. In these cases there is often no other way of making really good contacts, and it is therefore essential that these connecting lugs, or others of the same type and dimensions, should be used for connecting the meter to the testing cables. It would obviously be of advantage to testing authorities and to meter users, if the terminals of meters were standardised, as it would not then be necessary to unsweat the lugs from the main cables every time the meters were removed for testing, standard lugs being then a part of the test-room equipment. For meters to attain the correct steady temperature, particularly those of large current-carrying capacity, it is necessary to have both shunt and series coils excited, the meter running, and to take care that no undue heating takes place due to bad contacts at the connections. With the meter actually running there is also the further heating of the brake disc due to the eddy currents induced in it, and in some types of meter it is the temperature of the brake disc which is all-important.

Two-circuit Connections for Testing.-A very little consideration of the matter will be sufficient to show that meters of large watt capacity cannot be tested in the ordinary test-room unless some special means are adopted for artificially producing the load conditions. This point is quite familiar to those connected with meter testing, but as many who send meters to be tested appear to think that they are put on actual load a brief allusion to the testing circuit may be of use. Take, for example, the testing of a direct-current meter of the Thomson type, having a capacity of $\mathrm{I}, 000$ amperes and 500 volts. To test such a meter on actual load would require a 50o-k.w. generating set, and a suitable load for it. The whole effect in the meter is, however, produced by a current of 1,000 amperes in the series coil, and 500 volts applied to the pressure coil. So far as the actual working of the meter goes, therefore, it is immaterial how the current in the series coil is produced, so long as it is maintained at the required value. For economy and convenience in regulation, the series current is supplied at a low potential only. Thus if ro volts is the pressure of the current supply, the power required to test the meter under the equivalent of full-load conditions is $10 \times 1000+\frac{500^{2}}{R}$ watts, where $R$ is the ohmic resistance of the shunt coil of the meter-about ro k.w. in all.

In the case of direct-current meters the current and pressure for testing purposes are best obtained from secondary cclls, as grcater constancy is then maintained than is the case when they are obtained from!generators. A few cells of large capacity are required to supply the current for the series coils, and the requisite number of cells of small capacity to supply the pressure circuits.

For testing alternating-current meters the apparatus required is much more complicated than that required for continuous-current meters, it being necessary to provide means for adjusting the voltage, current, 
frequency, power factor, and possibly also the wave-form of the supply. The accurate conduct of the tests is also more difficult, since alternating current cannot be obtained directly from cells, and the steadiness of the supply is thus governed largely by the constancy of the speed of running machinery.

The necessary apparatus required for testing alternating-current meters includes ammeters, voltmeters, and wattmeters, all of which should have their accuracics unaffected by changes in frequency and wave-form, and be of suitable capacities ; a frequency meter, a phaseadjusting device, a means of telling whether the current is leading the voltage, or lagging behind it, and the necessary machinery for generating the alternating current.

It is necessary, again, here to emphasise the importance of accurate indicating instruments, and particularly in the case of the indicating wattmeter, this being, perhaps, the most important of the testing instruments used. A source of error in dynamometer wattmeters, and dyamometer watt-hour meters, which is at once most difficult to eliminate or to correct for, is due to the effect of eddy currents in portions of the instruments. From recent experience and tests carried out by the authors, they are of opinion that splitting the metal formers and supports in dynamometer wattmeters is not effective in eliminating eddy currents, and instruments of this type containing metal plates or formers, split or otherwise, will be liable to error introduced from the effect of eddy currents when the power factor is other than unity.

The accuracy of the ammeter and the voltmeter is of less importance than that of the indicating wattmeter.

Apparatus for Generating the Alternating Currenl.-Practically all modern altcrnating-current meters are of the watt-hour type, and hence, as in the case of direct-current tests, the two-circuit method of testing is employed. Unless suitable apparatus is installed, however, it is probably better, in cases where meters of only small capacities have to be tested, to use a single circuit of the correct frequency and voltage. More generally, however, arrangements have to be made for testing meters of large capacity for use on power circuits, as well as those employed for small lighting loads.

For the production of the necessary alternating current, one generator, with suitable transformers for the voltage and current circuits, or two generators of the same frequency, coupled rigidly together, one to supply the pressure and the other the current circuit, may be used. The generator for the current circuit may be either a low-voltage machine having the necessary current output, or, as is usually more convenient, it may be used in conjunction with a transformer having a low-voltage secondary winding. A transformer may also be used with the machine supplying the pressure circuits.

The method of regulating the current and voltage of the testing circuits is also important. If the loads on the machines are appreciable, compared with their rated output, it is advisable to work always with a 
strong field. The load current on the machines produces considerable field distortion with weak fields, and the wave-form of the generators is liable to be changed thereby. The field circuit of the generator or generators should therefore only be used for regulation over small ranges. Wide changes in voltage for the pressure circuit may be obtained by using an auto-transformer or other transformer with suitable tappings on the secondary, and changes in the current in the series circuit may be effected by means of a regulating resistance in the secondary or meter circuit of the low-voltage transformer. There is always a temptation to regulate the heavy secondary current in the series coils by means of a rheostat in the primary of the low-voltage transformer, but this procedure should always be avoided as it leads to variation in the wave-form of the secondary. Other advantages are gained by connecting the regulating resistance in the secondary circuit of the transformer. If the series coils of meters were to be connected directly to the secondary, and the regulation carried out entirely on the primary, by generator field regulation, the secondary circuit being one of considerable inductance, the current wave would differ from that of the pressure wave producing it if the pressure wave were not sinusoidal. The resistance in the secondary circuit tends to remedy this, and in addition keeps the phase of the secondary current fairly constant relatively to the phase of the volts applied to the pressure circuit.

When a transformer is used to supply the pressure circuit, it is necessary to have the transformer provided with suitable tappings on the secondary, as previously stated, and not to regulate the secondary voltage by means of a resistance in the primary circuit, such resistance changing the wave as in the case of the transformer for the series circuit. It is also important to note that resistances must never be connected in series with the pressure coils of induction meters for the purpose of regulating the voltage applied to the coils.

Frequency Regulation.-The adjustment of the frequency presents no difficulty in these days of interpole motors, and speed regulation from $25 \sim$ to roo $\sim$ is quite easily obtained on one machine by motor field regulation. Alteration of the speed by means of resistance in the armature circuit of the motor is very inconvenient, as the speed of the machine is then seriously affected by alteration of the load.

Frequency Meters.-Frequency meters of the vibrating reed type are found to be quite satisfactory, and instruments indicating quarterperiod differences may now be obtained.

Phase-adjusting .Devices, and Adjustment for Power Factor.-When the current and voltage for testing alternating-current meters are supplied from two separate sources, the power equivalent can only be determined by means of an indicating wattmeter, and the equivalent power factor is obtained from the readings of the wattmeter, ammeter, and voltmeter. In order to be able to adjust the power factor to the required value, some reliable form of phase-adjuster is essential.

The term "phase-adjuster" is intended to designate any arrange- 
ment of apparatus by which the phase relation of the volts and the amperes in the pressure and current coils respectively of the meter or group of meters, may be changed without appreciable alteration of the values of the volts and amperes in the circuit ; choking coils and condensers are therefore excluded.

The following methods of phase adjustment may be employed :-

(a) Two alternators of the same frequency coupled rigidly together, but with the couplings so arranged that the phase of the E.M.F. of one armature may be altered relatively to that of the E.M.F. of the second.

(b) Two alternators as in (a), but with the stator, instead of the rotor, of one machine arranged so that it may be turned relatively to the stator of the second machine.

(c) A phase transformer (static induction motor), the stator (or rotor) being supplied with multi-phase current, and the rotor (or stator) used to supply either the pressure or the current circuit of the meters. By moving round the rotor into different positions, the phase at the rotor E.M.F. may be altered relatively to that of the stator E.M.F.

(d) A multi-phase choking coil or auto-transformer, provided with suitable variable tappings, and connections made by means of brushes or switches.

(e) In certain cases different parts of a 3 -phase circuit may be used, giving phase differences of approximately $0^{\circ}, 30^{\circ}$, $60^{\circ}$, and $90^{\circ}$.

Of the foregoing methods, $(b)$-two machines, one provided with a moveable stator-is probably the ideal device.

The voltage of the machine supplying the pressure coils, and the current from the machine supplying the series coils of the meters, can be adjusted quite independently of each other, and then the movable stator can be turned, whilst the machine is actually running on load, until the required reading on the indicating wattmeter is obtained.

Such a set of machines, manufactured by the British Westinghouse Company, has been installed in the School of Technology, Manchester, and has been in use for the last sixteen months, proving extremely useful and convenient for the purpose.

The set comprises two similar alternators direct driven by a continuous-current motor arranged between them on the same bed-plate (Fig. I2). The motor is a 400-volt interpole variable speed machine of I3 B.H.P., with a speed regulation of 500 to 2,000 revs. per minute effected solely by variation of motor field current. The alternators are 6-pole 3-phase rotating armature machines, and six slip-rings are provided on each so that the armature coils may be connected either star or delta. The larger of the two alternators has a rating of 5 k.v.a. at 25 periods ( 500 revs. per minute), and the smaller one I k.v.a. at the same speed, and both machines are designed to give roo volts at this frequency. The larger machine is generally used in conjunction 
with a Westinghouse 5-k.v.a. oil-cooled transformer giving a normal secondary load current of $\mathrm{I}, \mathrm{Ooo}$ amperes. This transformer has two primary and two secondary windings. The primary windings can be connected in series or parallel for 200 or 100 volts respectively, and in the same manner the secondary can be arranged for lo volts or 5 volts. The usual connections are for 200 volts primary and 5 volts secondary, so that the load current taken from the machine is kept as low as possible.

The smaller alternator, which is used to supply the pressure circuits of the meters, is also used in connection with transformers when the voltage required differs considerably from the normal voltage of the machine. The field system, or stator of this machine, has been turned so as to fit into a circular seating on the bed-plate, and by means of wormgear may be turned through about 200 electrical degrees.

It is quite a simple matter to know if the phase of the voltage of the smaller machine is leading the phase of the current from the larger one or lagging behind it. By rotating the stator against the direction of rotation of the armature, the lead of the voltage is increased, or, by rotating with the direction of the armature the lead of the voltage is diminished, or the lag increased. Moreover, if any doubt exists as to whether the voltage is leading the current or lagging behind it, it is only necessary slightly to alter the position of the stator and to note the effect on the indicating wattmeter. If moving the stator against the rotation of the armature increases the reading on the wattmeter, then the voltage is lagging behind the current, and vice versâ.

The alternators are excited from secondary cells, and the result is a very steady supply of alternating current.

-Device (a)-two machines with adjustable coupling-is not so convenient as the above, since it is necessary to stop the machines to make the adjustments for power factor, and the adjustments can only be made by trial, as the phase of the voltage derived from each machine is somewhat varied by the variation in the nature and magnitude of the load on it.

Device (c)-phase transformer-is a very convenient one, and is, perhaps, best suited to supply the pressure circuit. An ordinary 3-phase induction motor with slip-ring rotor may be conveniently used, and has been found by the authors to give satisfactory results. It is necessary to prevent the rotor turning round under the action of the currents, and to provide a fine adjustment for altering the relative positions of the rotor and stator.

In use the stator is connected to a 3-phase generator, and one phase of the generator is then used in conjunction with a low-voltage transformer to supply the current circuit, the rotor voltage supplying the pressure circuit. Unless a regulating transformer is used in connection with the rotor circuit, it is a little inconvenient to adjust the current in the series circuit, and the volts on the pressure circuit exactly, because, unless the rated output of the generator is very large compared with the load required, alteration of the load current in the series circuit will

VOL. 47. 
vary the voltage applied to the pressure circuit, and alteration of the excitation of the generator will affect both the pressure circuit and the series circuit.

A combination of an induction motor and the two machines mentioned in method $(a)$ would eliminate most of the disadvantages possessed by either method used separately.

The use of a single-phase generator with a single-phase induction motor is not very satisfactory. It is found that when the rotating field in the stator of the induction motor is produced by splitting the single phase, the rotor voltage varies with the relative position of the rotor and stator, and thus the voltage is not maintained constant when adjustment is made for power factor. The method is therefore inconvenient.

Induction phase transformers with suitable connections and rotoradjusting devices may now be obtained from several makers, and it should be remembered that, within limits, the larger the rated output of the machine the more satisfactory will be the result. It was pointed out by Wild,* that with this form of phase adjuster the shape of the secondary wave will differ from that of the primary when the primary is not sinusoidal.

Device $(d)$-multiphase choking coil-is also a most convenient and satisfactory piece of apparatus if it is properly arranged and of ample dimensions.

A combined phase adjuster and voltage regulator of this type, possessing one or two somewhat uncommon features (probably because home made), has been in use for several years in the test-room of the Manchester Corporation Electricity Department, and has given excel: lent results. The construction and arrangement will be readily understood from the following brief description and reference to Fig. 13.

The main portion of the apparatus consists of an ordinary directcurrent drum armature, having a lap winding and slotted core, and originally used in a 10-H.P. 4-pole 400-volt motor. The armature has been surrounded with tightly fitting annealed iron stampings in the form of annular rings, built up to a depth nearly equal to the length of the core, and compressed between strong gunmetal end-rings. Suitable ventilating gaps are provided at intervals and the bolts drawing the end-rings together are bushed to avoid the production of eddy currents. The 3-phase supply mains are connected to the armature windings at 6 equi-distant points, and consequently induce a rotating magnetic field in the armature and annular ring. The magnetic circuit is practically all iron, as the joints are very good.

The armature is mounted with the axis vertical, in a stand forming part of a switchboard, and the commutator, or upper end of the shaft, is utilised as the support for a free fitting bush on which two radial arms are fitted. These arms may be moved relatively to each other, and may also be clamped together in any required position.

* Foumal of the Institution of Electrical Engineers, vol. 44, p. 224, I9ro. 


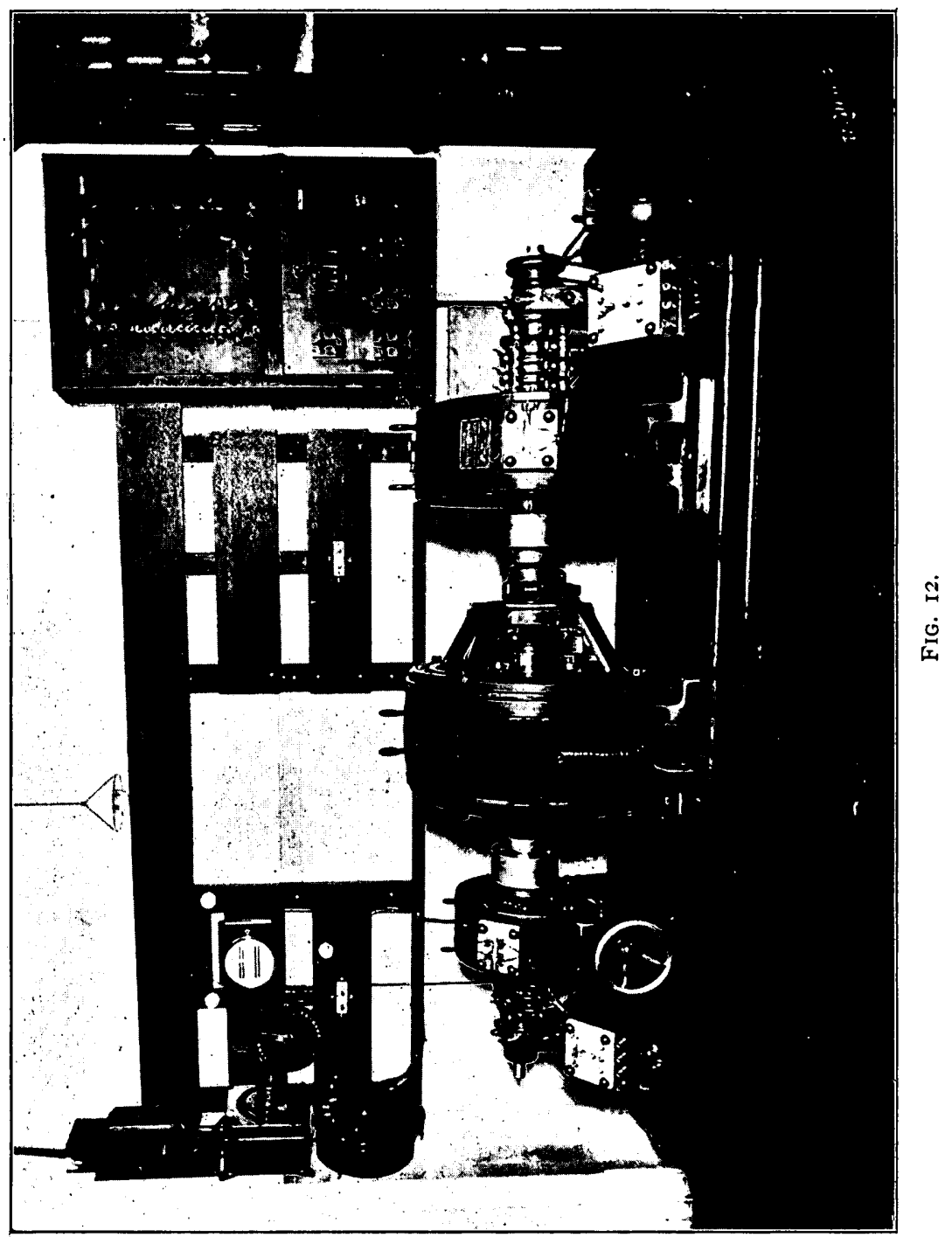



At the ends of the radial arms insulated brush-holder spindles are mounted, to which suitable brush-holders are attached. The brushes are of solid copper, and the portions bedding on the commutator are sufficiently thin to avoid bridging the insulation between segments. This is necessary as the brushes have to be moved over active

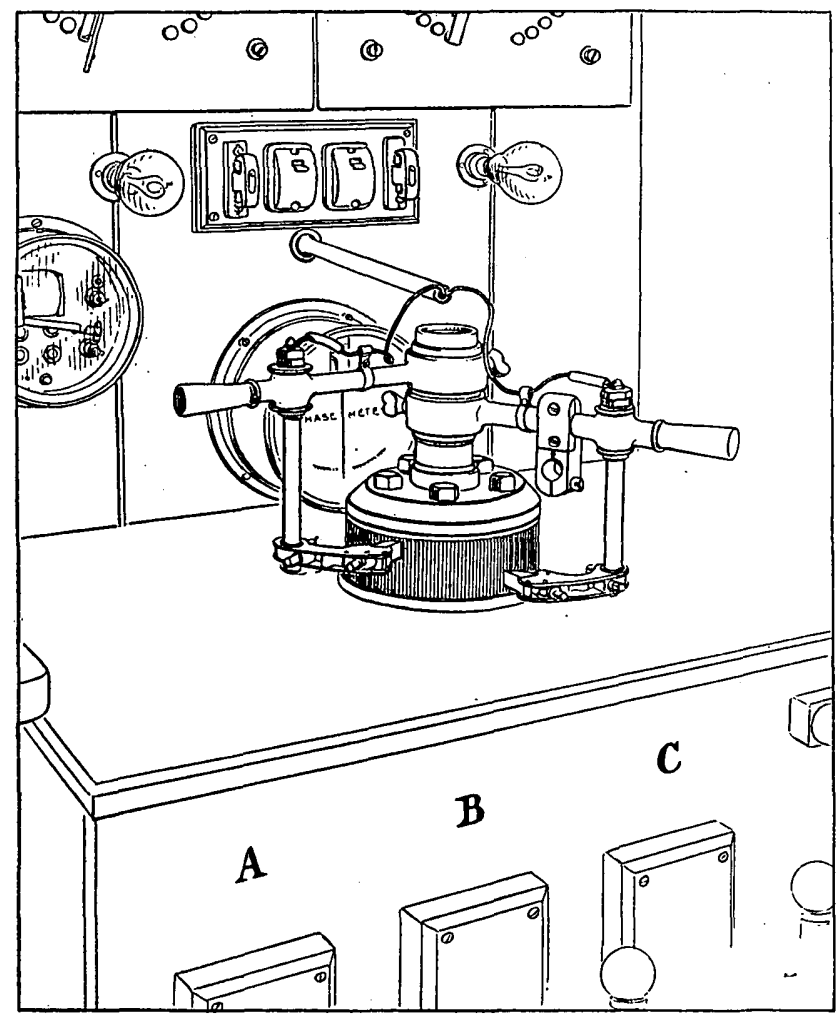

FIG. I3.

segments having an appreciable difference of potential between them.

It will thus be seen that by moving the radial arms relatively to each other, a large range of voltage adjustment may be obtained, and when the arms are clamped together, and the whole combination moved round the commutator, any desired phase displacement may be obtained between the voltage of the circuit fed from the movable brushes, and that of any other circuit connected to the same source of alternating current as the phase adjuster.

Usually only the two collecting brushes are used, but provision 
is made for attaching a third. The apparatus also acts as an autotransformer, and if the brushes are set with an angle of $90^{\circ}$ between them, a pressure higher than the supply voltage may be obtained, the ratio being approximately $2 / \sqrt{3}$, i.e., $\sin 90^{\circ} / \sin 60^{\circ}$ or $I^{\prime} 15$. Any lower voltage may be obtained by moving the brushes nearer together.

The phase adjuster is used to supply the pressure circuits of the meters, the series circuits being fed from the low-voltage (about 20 volts) secondary windings of a step-down transformer; with the primary connected to the same source of supply as the phase adjuster. As both the primary and secondary windings of this transformer are in two sections, it is possible to obtain a fairly constant secondary voltage with a wide range of primary volts.

When the phase adjuster is supplied with 3 -phase current at $3^{64}$ volts between lines, the no-load current $=4.45$ amperes per phase, and the no-load watts $=428$ total. The ratio of the secondary volts to the primary volts on open circuit, with the brushes $90^{\circ}$ apart $=420 / 364=$ $I^{\cdot}{ }^{5}$, this being in agreement with the theoretical value.

The adjustments for voltage and phase regulation are necessarily in steps, but a fine adjustment of the voltage is obtained by regulation of the alternator field, and the steps for phase adjustment are sufficiently small for practical purposes.

Records taken by the authors with an oscillograph show that even when an appreciable load is taken from the secondary or movable circuit of the phase adjuster, the secondary wave shows no apparent difference in shape from that of the primary wave.

With regard to the method of obtaining certain different phase relations by connecting the series coils of the meters to one part, and the shunt coils to another part of a 3-phase supply (as in (e) page 32 ), it may be pointed out that the theoretical phase :relations are much disturbed by the unbalanced nature of the load. This disturbance is particularly marked when connection is made to the neutral-point.

In this connection the results of some observations taken on the 3-phase alternator provided with the movable stator and previously described may be of interest.

The armature coils were star-connected, and the voltages and waveshapes of the different parts of the armature circuit were tested on open circuit, and also when loaded with lamps between two of the lines as shown in Fig. I4.

Waves I and 2, Fig. I4, represent the E.M.F. waves taken between $A$ and $B$ on open circuit and when loaded with a current of 4 amperes, respectively. The E.M.F. wave between neutral $D$ and the line on open circuit is not reproduced here, but is practically the same as wave $\mathrm{r}$. Waves 3,4 , and 5 , were taken across $\mathrm{AD}, \mathrm{BD}$, and $\mathrm{CD}$ respectively, with the load on $\mathrm{A} B$ as shown.

It will be noted that the voltages (Table I.) and also the waves between lines and neutral are very much disturbed by the unbalanced load.

Diagrams of the connections necessary for the testing of ampere- 


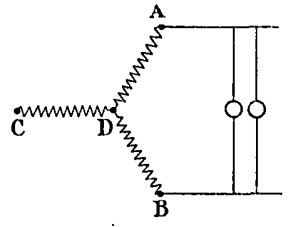

Connections.

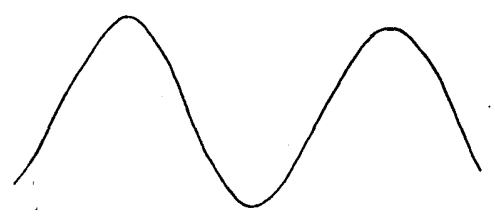

No. I.-Open-circuit Wave on A B.

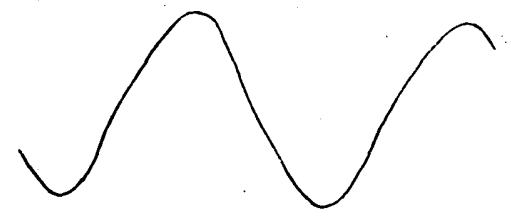

No. 2.-Wave on A B when Loaded.

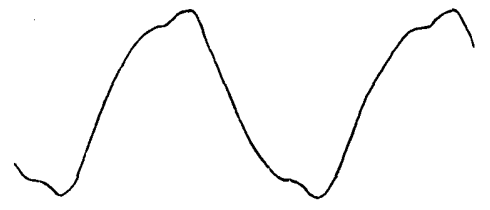

No. 3.-Pressure Wave on A D.

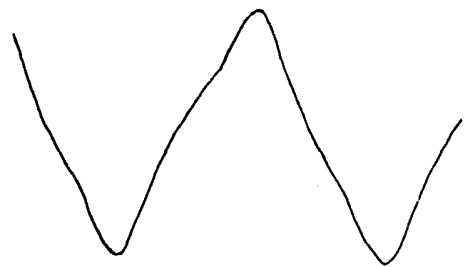

No. 4.--Pressure Wave on B D.

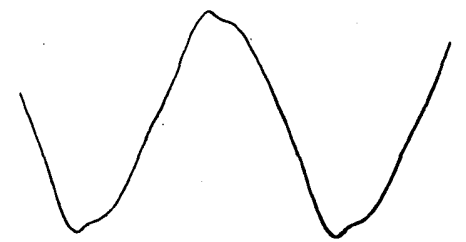

No. 5.-Pressure Wave on C D.

FIG. I4.

TABLE I.

\begin{tabular}{|c|c|c|}
\hline \multirow{2}{*}{$\begin{array}{c}\text { voltmeter connected } \\
\text { to- }\end{array}$} & \begin{tabular}{c} 
Volts, R.M.S. \\
on Open. Circuit. \\
\cline { 2 - 3 } A B
\end{tabular} & Machine Loaded. \\
\hline A C & II2.0 & $100 \cdot 5$ \\
B C & II2.0 & $98 \cdot 0$ \\
A D & II2.0 & 117.5 \\
B D & 65.0 & 54.5 \\
C D & 65.0 & 65.5 \\
64.5 & 63.0 \\
\hline
\end{tabular}


hour meters, direct-current watt-hour meters, and alternating-current watt-hour meters, are given in Figs. I5 to I8.

The testing of continuous-current meters presents no special difficulties, and the results of the tests carried out by testing authorities are rarely disputed.

With alternating-current meters, however, when the accuracy is in dispute the person responsible for the testing is immediately assailed

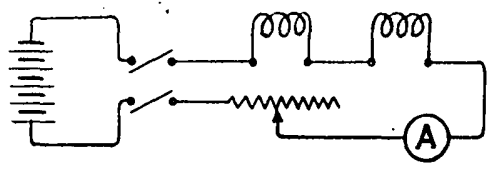

FIG. 15.

with questions relating to the method employed. These questions usually refer to the voltage, frequency, power factor, and wave-form of the testing circuits, and in the case of a polyphase meter, to whether it was tested on a single-phase or a multi-phase circuit.

Thus, whilst the accuracy of a direct-current meter is accepted, usually without question, that of an alternating-current meter is looked upon with a certain amount of doubt or suspicion.

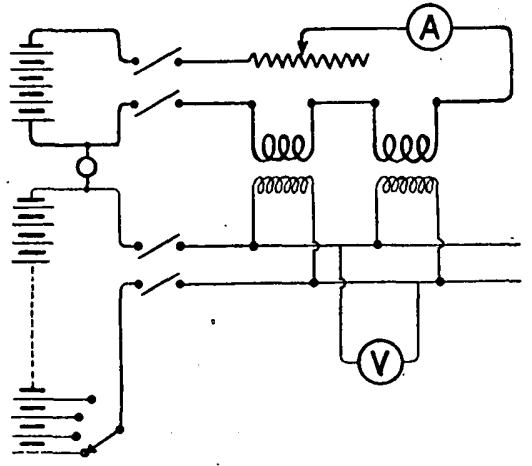

FIG. I6.

Resulls of some Tests on Alternating-current Induction Meters.-The tests described in the following section were carried out by the authors on a number of meters of the induction type supplied by different manufacturers. Most of the tests relate to the effects of wave-form and to the methods of testing polyphase meters.

The voltage and the frequency of the testing circuit could be maintained constant within about one-half of $\mathbf{I}$ per cent., and it was found by some preliminary tests that these variations could produce no measurable errors in the meters-assuming, of course, that the watts on the meters were kept quite constant by regulation. 
Effect of Wave-form.-When all other considerations for the inconsistencies in the results obtained when testing induction type meters fail in explanation, the inconsistencies are attributed to wave-form, mainly, perhaps, because the effect of change of wave-form is not easy to predict, and is generally unknown.

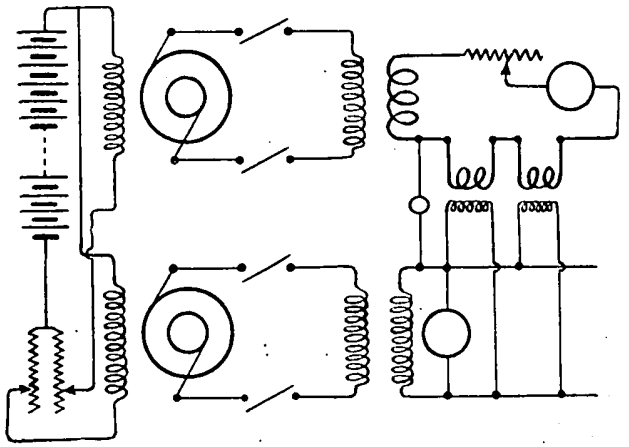

FIG. I7.

That alteration of the shape of the alternating-current wave does affect the accuracy of the registration of induction meters is shown by the results given below.

The small amount of information available relating to the effects

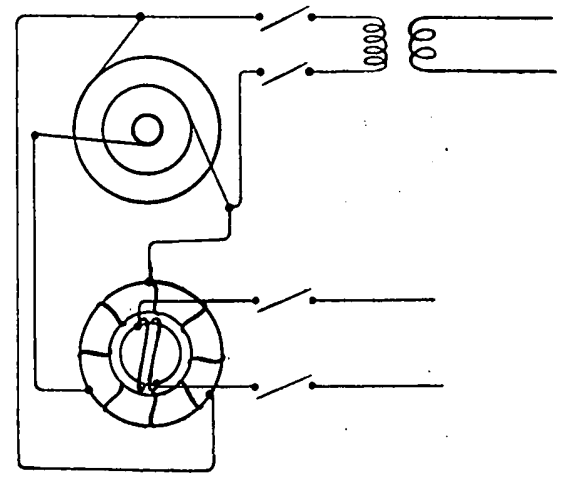

FIG. I8.

of variation of wave-form, is possibly due in some considerable measure to the lack of suitable apparatus for producing and examining waves of different shapes.

There are various methods of changing the shape of the wave given by a particular alternator, but it not infrequently happens that, whilst it is a comparatively easy matter to produce the change on the open- 
circuit wave of the machine, the new wave shape is not maintained when the machine is put on load.

A peaked wave may be obtained from a machine giving normally a sine wave, by using a transformer and connecting it to the machine with a resistance in series with the primary circuit. If the iron of the transformer is worked near its saturation point a very peaked wave is obtained from the secondary. Any appreciable load on the secondary, however, restores the secondary wave closely in shape to that of the machine if regulation is effected by means of the resistance in the primary.

For the purpose of the tests given in this paper experiments were made adopting the above method, and in order still further to change the wave, the secondary of the transformer used was connected in series with the alternator provided with the movable stator (in set previously described), the primary of the transformer being connected to the fixed stator machine in series with a resistance. By altering the relative phases of the wave from the secondary of the transformer and the alternator some most extraordinary shapes were obtained. It was found, however, that the circuit was a useless one for the purpose for which it was required, as the shape of the wave could not be maintained when load was put on.

Resort was then had to the method adopted at the National Bureau of Standards, Washington. By driving a second alternator at three times the frequency of the first, and connecting the armatures of the two machines in series, the third harmonic was superposed on the fundamental obtained from the movable stator machine. By this means the amplitude and phase of the harmonic could be altered relatively to the fundamental, and the wave was easily maintained when the machines were loaded. - The higher frequency alternating current was obtained from a small I-H.P. inductor-type alternator, driven at the correct speed by a chain and sprocket-wheels from the twin alternator set producing the lower frequency current. The waves from the machines are not quite sine waves, and the resultant waves indicate the presence of harmonics higher than the third.

A number of waves were tried, and note taken of the composition or mixing, and it was then found to be quite a simple matter to reproduce any wave previously used.

In order to avoid delay and possible alteration of physical conditions in the meters, the circuits were so arranged that by means of a changeover switch the change from the fundamental to the mixed wave could be quickly made, and by means of a second change-over switch the harmonic wave could be reversed so as to produce a peaked or a dimpled wave. The oscillograph used for observing the waves was kept continuously in circuit, so that there was never any doubt as to the shape of the pressure and current waves of the circuit. A lamp load was used, and the shape of the current wave was the same as that of the pressure wave in all cases where the power factor of the circuit was unity.

The results of the tests are given in Table II., and reproductions 
from photographs of the various waves, together with the proportion of harmonic to fundamental, are shown in Fig. I9. The percentage errors in the table represent the percentage deviation in the speed of the meter when tested with the various waves, from the speed obtained when tested with wave No. I, which represents the fundamental. After testing with each of the mixed waves a check test was made with the fundamental, and the results for this wave always showed extremely close agreement.

TABLE II.

Table showing the Percentage Deviation in the Speeds of the Meters when Tested with the various Waves, from the Speed when Tested with Wave No. I.

\begin{tabular}{|c|c|c|c|c|c|}
\hline \multirow{2}{*}{$\begin{array}{l}\text { Wave } \\
\text { No. }\end{array}$} & \multirow{2}{*}{$\begin{array}{l}\text { Power } \\
\text { Factor. }\end{array}$} & \multicolumn{4}{|c|}{$\begin{array}{l}\text { Percentage Deviation in Speed of Meters from Speeds } \\
\text { with Wave No. I. }\end{array}$} \\
\hline & & Meter A. & Meter B. & Meter C. & Neter D. \\
\hline I & Unity & - & 一 & - & - \\
\hline 2 & Unity & - & $0.7 \mathrm{~s}$ & I O $\mathrm{S}$ & $I \cdot 9 s$ \\
\hline $2 a$ & Unity & $0^{\circ}$ I $s$ & $0.3 s$ & I. $3 s$ & $0.8 \mathrm{~s}$ \\
\hline 3 & Unity & $0.9 s$ & I.OS & $3.5 s$ & $6 \cdot 6 s$ \\
\hline $3 a$ & Unity & $I \cdot I S$ & $0.3 s$ & $3.5 s$ & $2.0 s$ \\
\hline 4 & Unity & $\mathrm{I} \cdot 9 \mathrm{~s}$ & $\mathrm{I} \cdot 7 \mathrm{~s}$ & $7.5 \mathrm{~s}$ & II $7 \mathrm{~s}$ \\
\hline $4 a$ & Unity & $2 \cdot$ I $S$ & I.OS & $7 \cdot 4 s$ & $7 \cdot 3 s$ \\
\hline 5 & Unity & $6 \cdot 6 \mathrm{~s}$ & $44^{s}$ & $2 I \cdot 6 s$ & $27^{\circ} \circ \mathrm{s}$ \\
\hline $5 a$ & Unity & $6.2 s$ & 4.15 & $20 \cdot 3 s$ & $23.3 s$ \\
\hline 6 & Unity & - & - & - & $5.4 \mathrm{~s}$ \\
\hline $6 a$ & Unity & - & - & 一 & $3.4 s$ \\
\hline 7 & 0.8 & - & - & - & $O \cdot I$ \\
\hline $7 a$ & 0.8 & 一 & - & 一 & $I \cdot 9 s$ \\
\hline
\end{tabular}

$s=$ slow. $\quad f=$ fast.

Nos. 6 and $6 a$ are approximately of the same composition as 3 and $3 a$, with the phase of the harmonic altered.

No. 7 and $7 a$ are approximately of the same composition as 3 and $3 a$, but with inductive load.

It will be noted from the results that the accuracy of some makes of meters is more seriously affected by change of wave-form than the accuracy of others, but all are seriously affected with some of the waves used. The waves used are no doubt in some cases abnormal, but an attempt was made to obtain measurable errors, and this, it is seen, was quite an easy matter. 
The waves numbered $2 a, 3 a$, etc., are as nearly as possible of the same composition as those numbered 2, 3, etc., respectively, but with the harmonic waves reversed, or changed in phase by $180^{\circ}$.

The errors of two of the meters, $B$ and $D$, vary with the phase of the harmonic (relative to the phase of the fundamental) as well as the amplitude, and it will be noted that they register slower with a peaked wave than with a dimpled wave. Meters $\mathrm{A}$ and $\mathrm{C}$ register approximately the same on either form of wave. It may further be noted that when the power factor of the circuit is unity the errors increase, in all meters, as the proportion of the harmonic to the fundamental is increased, and that the meters register slower.

Meter D, which appears to be the most sensitive (of the meters tested) to changes in wave-form, was tested with waves of approxi-

\begin{tabular}{|c|c|c|c|}
\hline Wave No. & $\begin{array}{c}\text { Volts, R.M.S. } \\
\text { Fundamental. }\end{array}$ & $\begin{array}{c}\text { Yolts, R.M.S. } \\
\text { Harmonic. }\end{array}$ & $\begin{array}{c}\text { Volts, R.M.S. } \\
\text { Resultant. }\end{array}$ \\
\cline { 1 - 3 } I & I00 & - & I00 \\
2 & II2 & 36 & I00 \\
2A & II3 & 40 & 100 \\
3 & I09 & 50 & 100 \\
3A & III & 58 & I00 \\
4 & I05 & 68 & 100 \\
4A & I07 & 76 & I00 \\
5 & 92 & II2 & I00 \\
5A & 92 & II8 & I00 \\
\hline
\end{tabular}

mately the same composition as waves Nos. 3 and $3 a$, but with the phase of the harmonic wave intermediate between 3 and $3 a$. The results are given under waves 6 and $6 a$, but the actual waves are not reproduced. The two errors of the meter on these two waves are more nearly alike, and should be compared with the errors of this meter on waves 3 and $3 a$. The same meter (D) was also tested with waves having approximately the same composition as Nos. 3 and $3 a$, but with an inductive load at a power factor of about 0.8 . The results are given under waves 7 and $7 a$, and it will be noted that the errors come out comparatively small. It must be mentioned, however, that although the composition of the wave was arranged to be approximately the same as wave No. 3 , the actual resulting wave on the inductive load was different in shape from that of No. 3, and further, the current wave differed in shape from the pressure wave. These waves were 


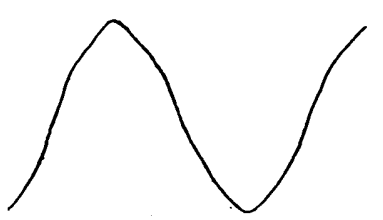

Open-circuit Wave of No. I.

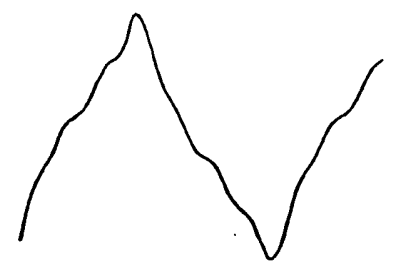

No. 2. $-\mathrm{V}=100, \mathrm{~V}_{\mathrm{F}}=\mathrm{I} 12, \mathrm{~V}_{\mathrm{H}}=36$.

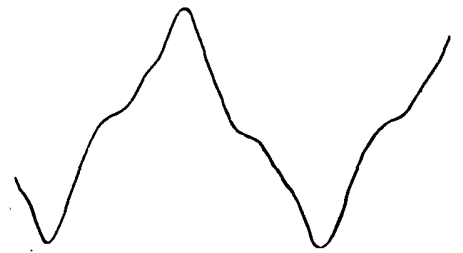

No. 3. $-\mathrm{V}=100, \mathrm{~V}_{\mathrm{F}}=\mathrm{rog}, \mathrm{V}_{\mathrm{H}}=50$.

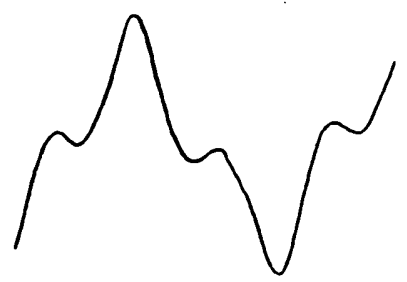

No. $4 .-\mathrm{V}=100, \mathrm{~V}_{\mathrm{F}}=105, \mathrm{~V}_{\mathrm{H}}=68$.

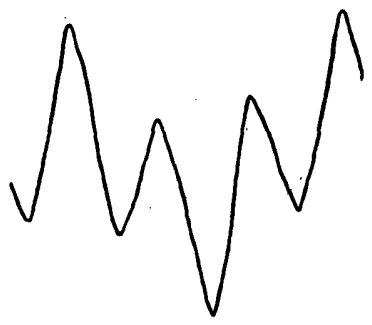

No. 5.-V $=100, V_{F}=92, V_{H}=I 12$.

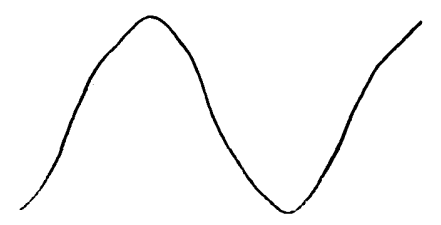

No. I. $-\mathrm{V}=$ IOO.

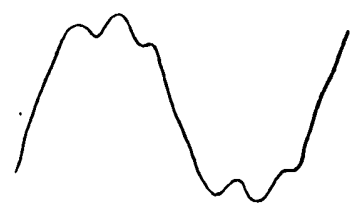

No. $2 A .-V=I 00, V_{F}=I I 3, V_{H}=40$.

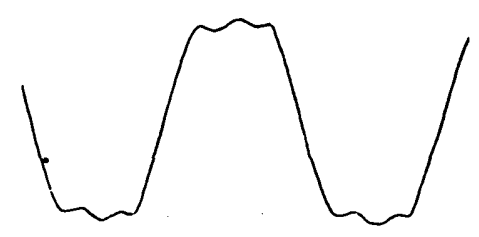

No. $3 A .-V=I 00, V_{F}=I I I, V_{H}=5^{8}$.

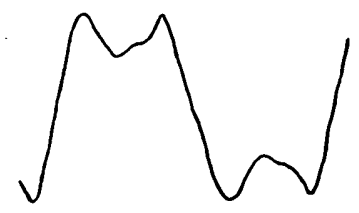

No. $4 \mathrm{~A} .-\mathrm{V}=100, \mathrm{~V}_{\mathrm{F}}=107, \mathrm{~V}_{\mathrm{H}}=76$.

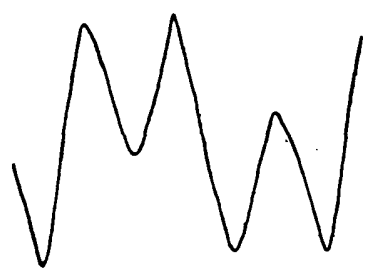

No. 5A.- $\mathrm{V}=\mathrm{I00}, \mathrm{VF}_{\mathrm{F}}=92, \mathrm{~V}_{\mathrm{H}}=\mathrm{II} 8$.

FIG. I9.

V = R.M.S: of Resultant Voltage.

$V_{F}=$ R.M.S. of Fundamental Voltage.

$V=$ R.M.S. of Harmonic Voltage. 
not photographed, but it may be mentioned that they appeared even more abnormal than No. 3 .

The authors are not prepared at present to advance any theory for these effects of changes in wave-form, but several possible causes suggest themselves, such as :-

Alterations in the nature of the rotating or shifting magnetic fields.

Effects on the fluxes in the cores by changes in the eddy currents and hysteresis of the iron.

Effects on the quadrature adjustments.

Effects of frequency; it will be noted that as more of the harmonic wave is added, the resultant wave approaches more nearly to the triple-frequency wave of the harmonic.

From the results it would appear that there is a limit to the amount of variation of the wave-form of the circuit on which induction meters are used, if the errors of the meters are to be kept within specified limits.

The case is not adequately met by testing the meters on a waveform the same as that with which they will eventually be used, because the wave-form of a generator is usually somewhat modified by the load.

A meter of the dynamometer type was also tested, and it was found c that the errors with the various. waves were so small as to come within the limits of errors of observation. This result was anticipated, as the standard indicating wattmeter used for the tests was a Duddell-Mather instrument of the dynamometer type.

Testing Polyphase Meters. - The 2-meter method of measuring the energy in a 3 -phase 3 -wire circuit has been previously referred to as constituting the best standard practice, and it is the only one dealt with in this section.

All the various tests described below have been made on the twin, or combination, type of meter, with a common set of integrating dials.

If these polyphase meters were perfect, their registrations would represent the total energy of the circuit, independently of the nature of the load, whether balanced or unbalanced, and of the value of the power factor. In order that the meters may register accurately, each of the two single-phase elements of which such meters are composed, must be unaffected by the alternating fluxes set up in the other element. It must be remembered that when two single-phase meters are used for measuring the energy in a 3 -phase 3 -wire circuit, the phase difference between current and voltage is not the same ffor both meters. Thus in a polyphase meter, used on a 3-phase circuit of unity power factor, each element is connected to a circuit of power factor 0.866 , but in one element the current through the series coil is leading the voltage by $30^{\circ}$, while in the second the current is lagging behind the voltage by $30^{\circ}$. 
Fig. 20: shows how the power factor of a balanced 3-phase load affects the ratio of the watts on the two meters, and also how the

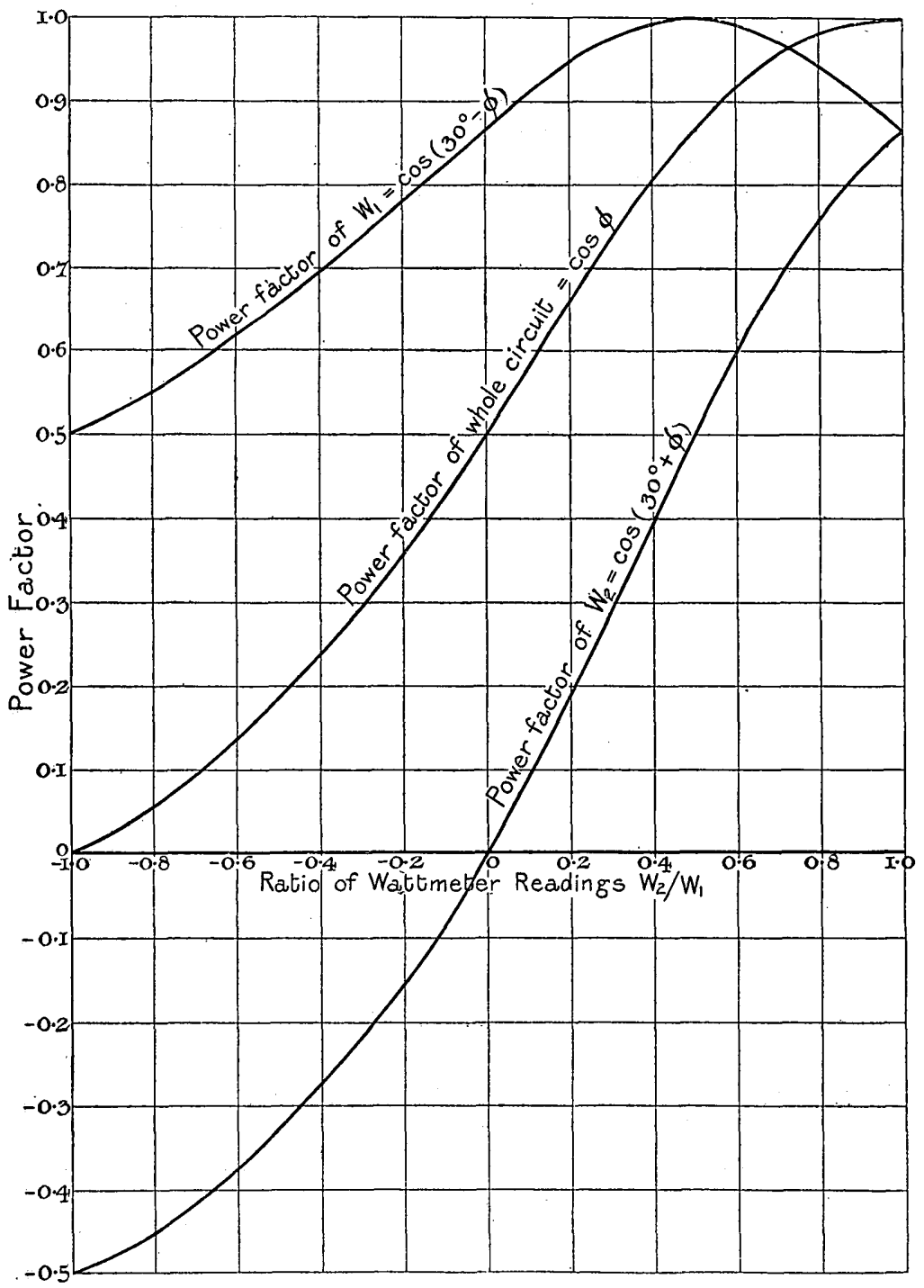

FIG. 20.

equivalent power factor for each meter is affected by the power factor of the load.

In this connection it may be noted that the power factor of one of 
the meter circuits may have a very low, or even a negative value, and under these conditions the meter may have a rather large error, but as it only integrates a correspondingly small proportion of the total power in the circuit, the accuracy of the 2-meter combination may still be very good.

Now, since two single-phase meters may be used to measure the energy, it should be possible to test a polyphase meter by testing each element separately as a single-phase meter, and this method could certainly be adopted if there were no interaction between the two elements. Unfortunately, however, there is always the possibility that

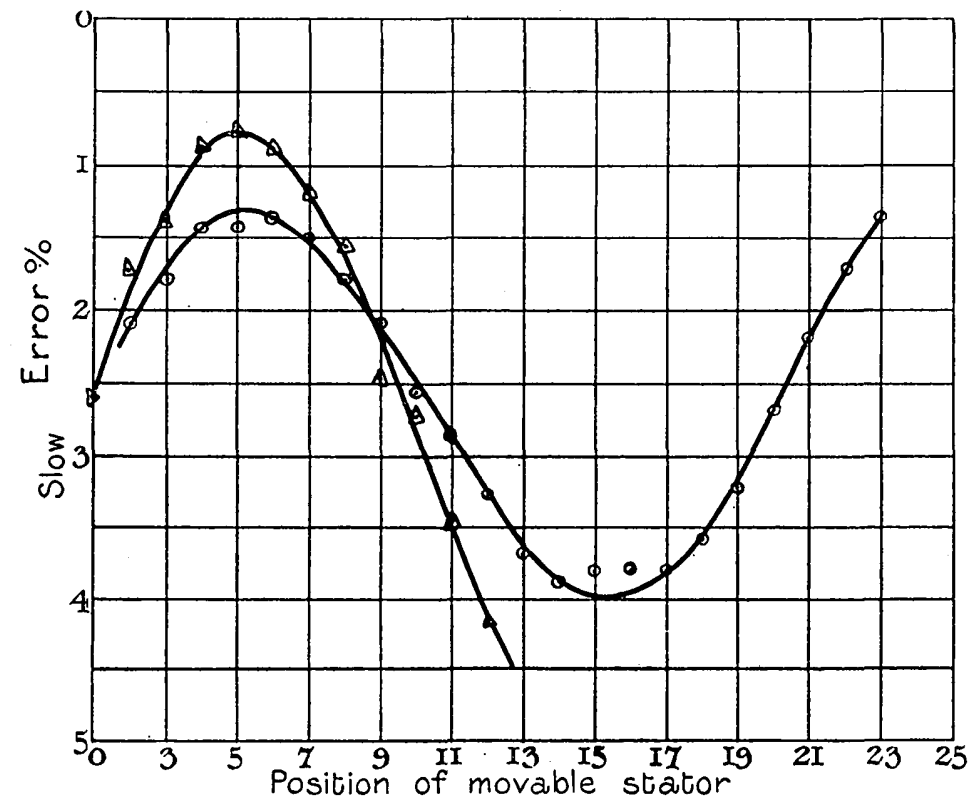

FIG. 2I.

the registrations of either of the two elements will not be unaffected by variations due to load on the other.

The testing of polyphase meters therefore presents considerable difficulties, and it is, in the authorș' opinion, very doubtful whether it is possible to test a polyphase meter so that the result may be relied on to the same degree of accuracy as is the case with a single-phase meter. If the meter cannot be tested as two separate, single-phase meters, it is doubtful whether it can possibly be a true polyphase meter.

With the object of clearing up this point, a number of induction type polyphase meters were tested on a 3-phase circuit, and on different arrangements of single-phase circuits. The results obtained 
showed considerable variation in the accuracy of the meters when tested on the various circuits.

Tests for Interaction between the Elements of Polyphase Meters.Interaction between the fluxes of the two elements was not at first suspected, but it was afterwards found to exist from the fact that the speed of the meter was appreciably affected by the relative phases of the fluxes of the two elements.

In order to determine the effect on the speed of the meter, caused by altering the relative phases of the loads on the two elements, each element was supplied separately with a definite load, one from each of the two machines described on page 32, Fig. 12, and, keeping the load on each element constant, a series of observations was taken with the movable stator of the one machine in a number of successive positions. The results for two meters of the two-disc type are shown by the curves Fig. 21.

It is to be noted that the maximum and minimum speeds of the meter occur at a difference of phase of $180^{\circ}$ between the loads. To verify this, the movable stator of the machine was adjusted until the maximum speed of the meter was observed. The connections to the machine were then reversed. This had the effect of bringing the speed down to its minimum. The connections to the second machine were then also reversed, and the speed again rose to the maximum, thus verifying the fact that the maximum and minimum speeds were obtained by an alteration of the phase of the power on one element by $180^{\circ}$.

The fact that the change of phase difference producing maximum effect was $180^{\circ}$ led to the conclusion that there was probably magnetic interaction between the two elements.

In making subsequent tests, on other meters for this magnetic interaction it was found unnecessary to determine curves as in Fig. 2 r. The maximum and minimum speeds for a meter were equally well determined by connecting the two current coils in series, and the two pressure coils in parallel with each other respectively, and using one single-phase alternating-current supply. After noting the speed for a particular load, the connections to the current and pressure coils of one element of the meter were reversed, and the speed again noted with the same load.

For the purpose of the authors' investigation, one of the manufacturers kindly made up a special two-disc meter, so arranged that the space between the two elements could be altered at will.

With this it was found that when the elements were separated as far as possible, the effect of interaction was about one-half of what it was when the elements were in their normal position.

Some effects of this interaction on the registrations of different tnakes, of meters are shown in Tables III. to VI.

It may be mentioned that only one of the meters tested was free from this defect of interaction; but as it was found to be present in other meters of the same type and make, it appears that even the meters of this firm cannot be said to be free from the defect. 


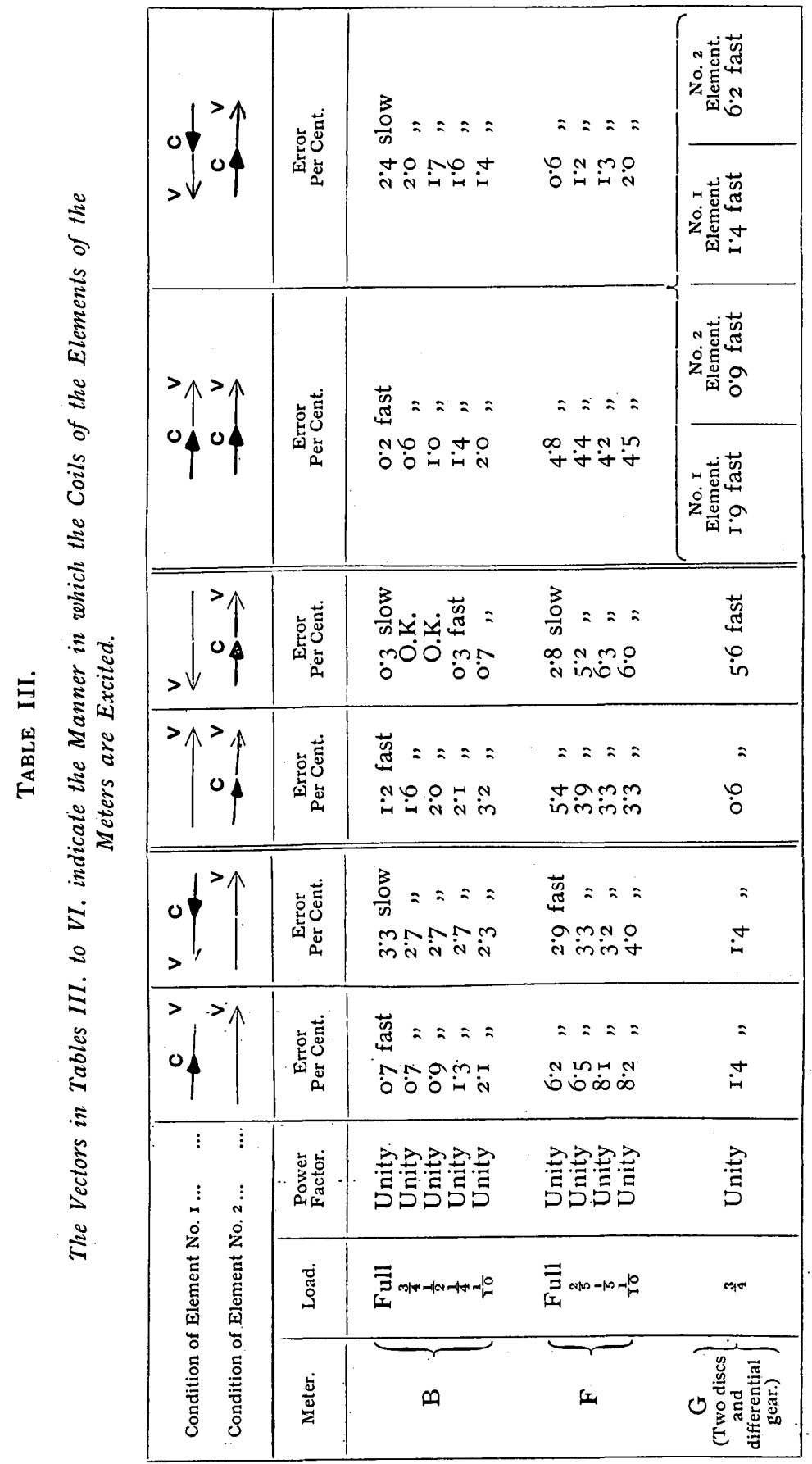




\begin{tabular}{|c|c|c|c|c|c|}
\hline 0 & 悹节 & $\begin{array}{l}\ddot{n} \\
\stackrel{n}{m} \\
m\end{array}$ & 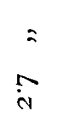 & $\stackrel{i}{i}$ & $\begin{array}{l}3 \\
3 \\
0 \\
0 \\
0 \\
0\end{array}$ \\
\hline 0$\}_{1}^{>}$ & 崖 & 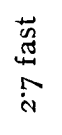 & $\begin{array}{l}a \\
m\end{array}$ & $\begin{array}{l}2 \\
0 \\
0\end{array}$ & $\begin{array}{l}3 \\
\frac{3}{n} \\
\text { in }\end{array}$ \\
\hline o & 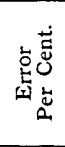 & 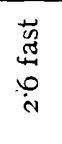 & $\begin{array}{l}= \\
\dot{\sigma}\end{array}$ & $\begin{array}{l}= \\
\dot{\infty}\end{array}$ & $\begin{array}{l}3 \\
0 \\
0 \\
1 \\
1\end{array}$ \\
\hline$\uparrow_{\uparrow} \stackrel{0 \leftrightarrow}{\longrightarrow}$ & 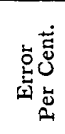 & $\begin{array}{l}3 \\
0 \\
0 \\
0 \\
0\end{array}$ & $\begin{array}{l}= \\
10 \\
0\end{array}$ & $\begin{array}{l}= \\
\dot{i}\end{array}$ & $\dot{4}$ \\
\hline 0 & 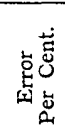 & $\begin{array}{l}3 \\
\frac{3}{15} \\
0 \\
0\end{array}$ & $\begin{array}{l}= \\
\infty \\
0\end{array}$ & $\begin{array}{l}= \\
i n \\
i n\end{array}$ & $\begin{array}{l}= \\
\dot{\infty}\end{array}$ \\
\hline$\left.{ }_{0}^{>} \uparrow\right\}^{0}$ & 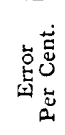 & 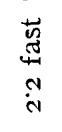 & $\begin{array}{l}= \\
\dot{\sigma}\end{array}$ & $=$ & $\begin{array}{l}3 \\
\frac{0}{n} \\
10 \\
\dot{7}\end{array}$ \\
\hline${ }^{>} \uparrow>V$ & 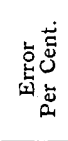 & $\underset{m}{\stackrel{\vec{n}}{m}}$ & $\begin{array}{l}= \\
\dot{a}\end{array}$ & $\begin{array}{l}= \\
\stackrel{\infty}{i}\end{array}$ & $\begin{array}{l}3 \\
0 \\
n \\
i n\end{array}$ \\
\hline${ }^{>} \uparrow>\uparrow$ & 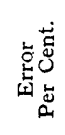 & 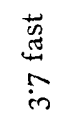 & $\begin{array}{l}= \\
\text { in }\end{array}$ & $\hat{i}$ & $\begin{array}{l}3 \\
\frac{3}{4} \\
\alpha \\
\alpha\end{array}$ \\
\hline$\uparrow_{0}^{>\uparrow}$ & 咅 & $\begin{array}{l}\stackrel{+}{0} \\
\stackrel{n}{N} \\
\text { in }\end{array}$ & $\begin{array}{l}= \\
\text { in }\end{array}$ & $\begin{array}{l}= \\
\dot{\sigma}\end{array}$ & $\begin{array}{l}\vec{z} \\
\frac{0}{n} \\
\dot{y}\end{array}$ \\
\hline${ }_{0} 01$ & 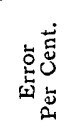 & 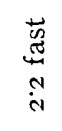 & $\begin{array}{l}= \\
\stackrel{0}{i}\end{array}$ & $=$ & $\hat{\vdots}$ \\
\hline $0 \uparrow$ & 范 & 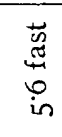 & $\begin{array}{l}= \\
\text { in }\end{array}$ & 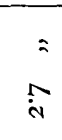 & 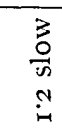 \\
\hline 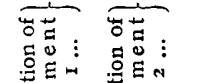 & 峞 & $\equiv$ & 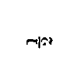 & $-4 \pi$ & 1 \\
\hline 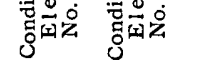 & & & $r_{4}^{4}$ & & |c \\
\hline
\end{tabular}

VOL. 47. 


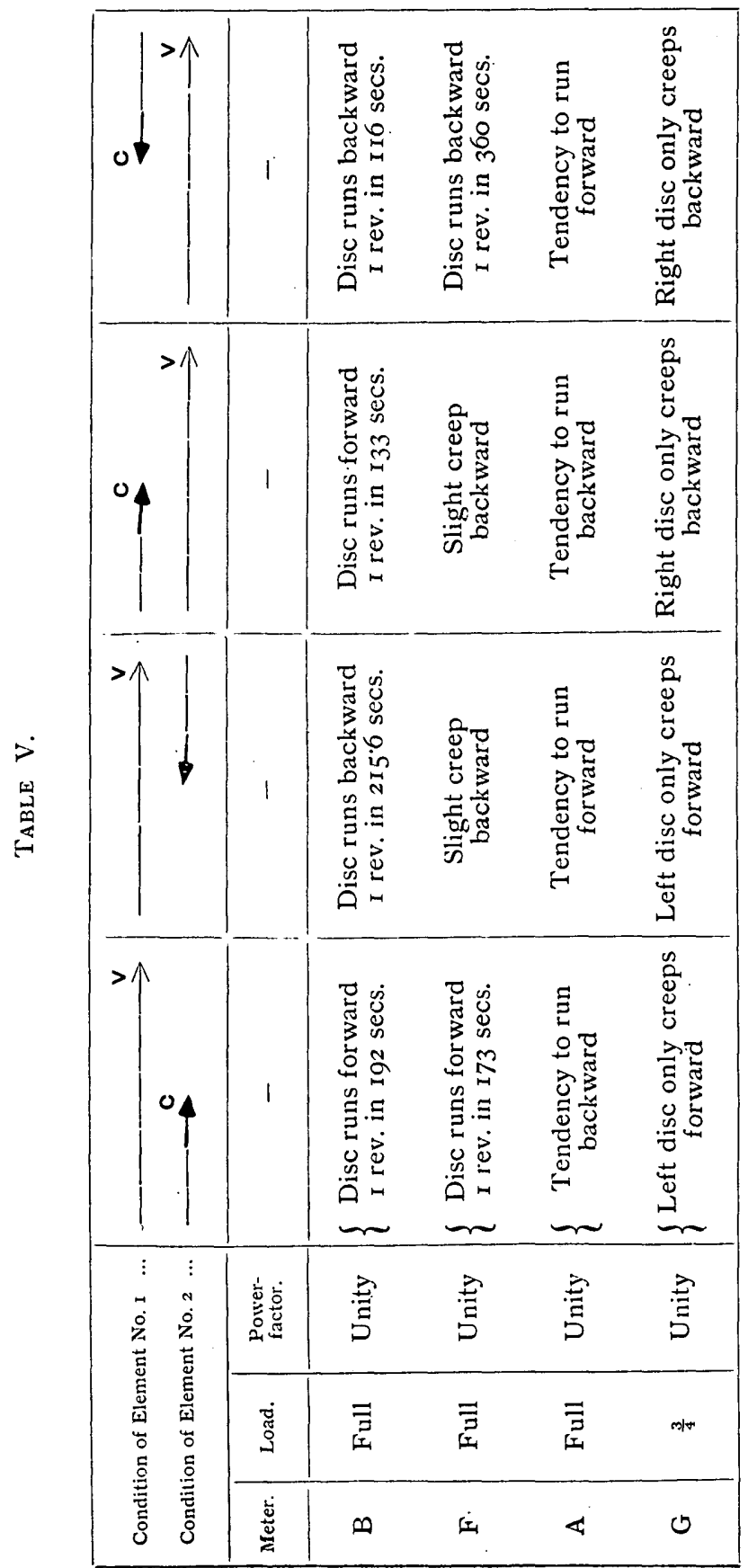




\begin{tabular}{|c|c|c|c|c|c|}
\hline & 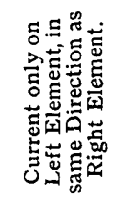 & 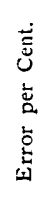 & 1 & $\begin{array}{l}3 \\
0 \\
0 \\
i n \\
i n\end{array}$ & 1 \\
\hline $\begin{array}{l}\stackrel{\Xi}{\Xi} \\
\Xi\end{array}$ & 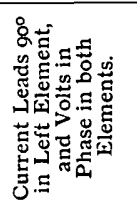 & 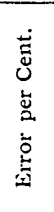 & 1 & $\begin{array}{l}3 \\
\frac{3}{0} \\
0 \\
n \\
i=1\end{array}$ & 1 \\
\hline 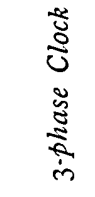 & 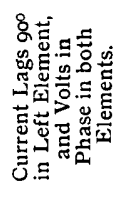 & 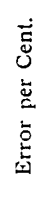 & 1 & 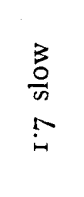 & 1 \\
\hline $\begin{array}{l}\tilde{3} \\
\tilde{5} \\
\overline{5} \\
\tilde{5} \\
\tilde{3}\end{array}$ & 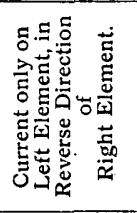 & 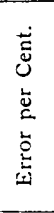 & | & $\frac{1}{0}$ & 1 \\
\hline 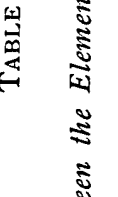 & 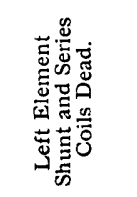 & 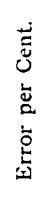 & 1 & $\begin{array}{l}3 \\
\frac{3}{0} \\
0 \\
0 \\
0\end{array}$ & 1 \\
\hline 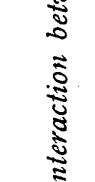 & 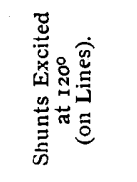 & 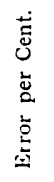 & $\begin{array}{l}\frac{3}{0} \\
\frac{0}{n} \\
\stackrel{0}{-1} \\
\dot{-1}\end{array}$ & $=$ & $=$ \\
\hline 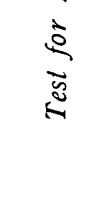 & 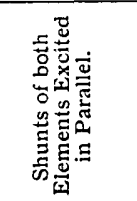 & 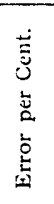 & $\begin{array}{l}z \\
\frac{\partial}{n} \\
0 \\
0\end{array}$ & $\begin{array}{l}\hat{\sigma} \\
\dot{0}\end{array}$ & $\begin{array}{l}= \\
\stackrel{i}{i}\end{array}$ \\
\hline & & & 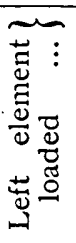 & 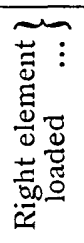 & 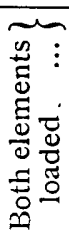 \\
\hline
\end{tabular}


Extra Braking Torque in Induction Polyphase Meters when both Elements are Loaded.-The driving fluxes of the coils in meters of the induction type also act as braking fluxes. The braking flux is thus due partly to the load, as well as to the permanent magnet; this results in the braking torque not being simply proportional to the speed, but varying with the load.

When testing one element only of the meter, it is essential to have the pressure coil of the second element excited, because the flux produced thereby acts as a brake flux on the disc, and in actual use both the pressure coils of the meter are excited.

Now, if a speed of $n$ revolutions per minute is obtained when one element only is loaded, a speed of $2 n$ revs. per minute would be obtained if twice the driving torque were applied without altering the total brake flux. If an additional load equal to that already acting on one element of the meter be applied to the second element, the driving torque will be practically doubled; but the addition of the current flux in the second element will also add to the brake-field. Owing to the increased braking flux, the braking torque will rise to double its original value, at a speed which is less than twice the original speed of the meter.

If equal speeds are obtained with equal loads on each element separately, it follows that when equal loads are applied to both elements together, the speed of the meter will be less than twice the speed obtained with either element separately. Or, when both elements are loaded, the speed is less than would be obtained by calculation from the speeds of each element taken separately on their respective loads.

The above effect is most marked at the higher loads. It may, however, in some cases be neutralised by the effect of the magnetic interaction previously referred to, and the speed of the meter in such a case may be even higher proportionately when both elements are loaded than when only one is loaded.

From a testing point of view, especially with meters of large capacity, it is of great importance to be able to test with single-phase current. To have to set up a double 3-phase circuit for the current and pressure would be most inconvenient, and, moreover, as has been previously stated, if the meter cannot be tested as a single-phase one, it is doubtful whether it can possibly be a true polyphase meter.

When series transformers are used with the meters, the meters are usually of a sinall enough capacity to test directly as 3-phase meters, and the ratios of the series transformers at the various loads can be determined separately; but even this method is not satisfactory on account of the phase error in the transformers, which it is difficult to measure, and which varies with the load.

Shunt transformers can usually be tested for ratio and the necessary corrections applied to the calibration of the meter, because they will, as a rule, be used at, or near, one stated voltage, and the phase error in a good shunt transformer is negligibly small if it is not overloaded.

In conclusion, the authors regret that the investigations on the effects 
of wave-form, etc., are not more complete, but while the results given are comparatively few, the number of tests carried out in order to obtain and verify them has been very large. For example, much time was spent in trying to reconcile, by experiments, the inconsistent results obtained in the tests on polyphase meters, before it was even suspected that there was the appreciable magnetic interaction afterwards discovered. The authors have decided to continue the investigations, and to deal also with meters when used with current and pressure transformers.

The authors wish to make acknowledgment to the Principal, and the Committee of the Manchester School of Technology, and to the Chief Electrical Engineer of the Manchester Electricity Department, Mr. S. L. Pearce, for facilities for carrying out the tests detailed in the paper. To Professor Schwartz and Mr. C. F. Smith for reading through the manuscript and offering many suggestions. To Messrs. The British Westinghouse Company, The Electrical Company, Siemens Bros., Ferranti Ltd., and The Aron Meter Company, for the loan of meters ; and to Messrs. P. Kemp, J. Davies, G. W. Wadsworth, O. Howarth, A. M. Doig, and F. H. Williams, for assistance in the experimental work.

\section{Discussion.}

Mr. S. H. Holden : I have studied this paper with very great interest. It contains a very large amount of useful matter, and tempts discussion at almost every point. I am very much interested in the work on the effect of wave-form upon the accuracy of alternatingcurrent meters. It is quite a usual thing for purchasers of meters to specify that they are to be unaffected by variations in wave-form, but they do not give the least hint as to what variations are to be looked for or how the meters are going to be tested to see whether they conform to the specification. Further, the British Standard Specification does not give any assistance in this direction, and I hope that the work which the authors have done may lead to greater precision in this department. With regard to shunts to mercury meters, the authors say that these may have certain possible advantages. I think it would be quite fair to say that those are positive advantages, as for the most part there is no doubt about them. Shunted mercury meters have been in use to my knowledge for fourteen or fifteen years at least, and I have known of very many cases where meters have been tested after seven or eight years' use and are still quite accurate. The resistance of the mercury in a meter is a very small proportion of the total : the actual resistance is mainly in the coils and the connections, and even if it did vary, and vary very considerably-though I do not think it does-it would have very little effect on the accuracy of the meter. A mercury meter to carry I,000 amperes without a shunt would be quite a big thing, more like a gas meter than an electricity meter. I should like to ask whether the experiments upon which the authors based their opinions were conducted upon the latest type of mercury watt- 